\title{
A review of current trends in three- dimensional analysis of left ventricular myocardial strain
}

\author{
Yosuke Nabeshima ${ }^{1 *}$ D, Yoshihiro Seo $^{2}$ and Masaaki Takeuchi ${ }^{3}$
}

\begin{abstract}
Three-dimensional (3D) left ventricular (LV) myocardial strain measurements using transthoracic 3D echocardiography speckle tracking analysis have several advantages over two-dimensional (2D) LV strain measurements, because 3D strain values are derived from the entire LV myocardium, yielding more accurate estimates of global and regional LV function. In this review article, we summarize the current status of 3D LV myocardial strain. Specifically, we describe how 3D LV strain analysis is performed. Next, we compare characteristics of $2 \mathrm{D}$ and $3 \mathrm{D}$ strain, and we explain validation of 3D strain measurements, feasibility and measurement differences between 2D and 3D strain, reference values of 3D strain, and its applications in several clinical scenarios. In some parts of this review, we used a meta-analysis to draw reliable conclusions. We also describe the added value of 3D over 2D strain in several specific pathologies and prognoses. Finally, we discuss novel techniques using 3D strain and suggest its future directions.
\end{abstract}

Keywords: 3D echocardiography, Speckle tracking, Left ventricular strain

\section{Introduction}

During the last two decades, two-dimensional (2D) myocardial strain measurements from 2D echocardiography (2DE) speckle tracking analysis have become an established technique for quantifying left and right heart chamber function. Their usefulness has been validated to 1 ) detect subtle heart chamber dysfunction [1-3], 2) evaluate the extent and severity of heart disease [1-3], and 3) predict future outcomes in various cardiovascular pathologies [2]. All ultrasound vendors now have their own proprietary 2DE speckle tracking analytical software for the left ventricle, and some vendors have launched fully automated 2D strain analytical software employing artificial intelligence. Since the left ventricular (LV) myocardium consists of three different myocardial

\footnotetext{
* Correspondence: y.nabeshima1016@gmail.com

${ }^{1}$ Second Department of Internal Medicine, School of Medicine, University of Occupational and Environmental Health, 1-1 Iseigaoka, Yahatanishi, Kitakyushu 807-8555, Japan

Full list of author information is available at the end of the article
}

layers that contract in different directions simultaneously, accurate assessment requires three-dimensional (3D) analysis. Three-dimensional echocardiography (3DE) datasets with 3D speckle tracking analytical software have made it possible to perform clinical 3D strain analysis during the last decade [3-5]. 3D strain software offered by most ultrasound companies is designed to measure LV myocardial strain; thus, this review manuscript focuses only on 3D LV strain. For simplicity, strain values in each direction are presented as absolute values in the text, figures, and tables.

\section{D strain analysis}

3D strain analysis starts by generating a region of interest (ROI), followed by segmentation of the left ventricle into a 16- or 17-segment model. The size of the ROI differs among 3D strain analytical software packages (LV subendocardial myocardium or the entire LV myocardium). Moreover, some software uses a library of various LV shapes from a large volume of patient data, and

(c) The Author(s). 2020 Open Access This article is licensed under a Creative Commons Attribution 4.0 International License, which permits use, sharing, adaptation, distribution and reproduction in any medium or format, as long as you give appropriate credit to the original author(s) and the source, provide a link to the Creative Commons licence, and indicate if changes were made. The images or other third party material in this article are included in the article's Creative Commons licence, unless indicated otherwise in a credit line to the material. If material is not included in the article's Creative Commons licence and your intended use is not permitted by statutory regulation or exceeds the permitted use, you will need to obtain permission directly from the copyright holder. To view a copy of this licence, visit http://creativecommons.org/licenses/by/4.0/ The Creative Commons Public Domain Dedication waiver (http://creativecommons.org/publicdomain/zero/1.0/) applies to the data made available in this article, unless otherwise stated in a credit line to the data. 
selects an appropriate LV shape to generate an ROI in each case (artificial intelligence). While 2D speckle tracking analysis pursues areas that contain specific natural acoustic markers, frame by frame within the ROI (pattern matching), 3D speckle tracking analysis tracks cubes with specific 3D patterns of acoustic markers within the ROI (block matching) to calculate global and regional 3D strain components (Fig. 1). Since the endocardial border is tracked throughout the cardiac cycle, the software also provides time domain LV volume curves from which the LV ejection fraction (LVEF) is calculated. In addition to longitudinal strain, circumferential strain, and radial strain, 3D strain software provides new deformation parameters, such as area strain and principal strain (Figs. 1, 2, 3 and 4). Area strain is determined as the percentage decrease in the size of endocardial (or mid-myocardial) surface area, defined by vectors of longitudinal and circumferential deformation at end-systole from its original area at end-diastole [6].
Principal strain represents the major direction and magnitude of the deformation in which no shear strain occurs. It reflects longitudinal, circumferential, and torsional deformation; therefore, it can represent dynamic 3D movements of the left ventricle [7].

It is important to note that each software system has its own proprietary tracking algorithm, with different analytical approaches. Although strain values should be 0 at the start and end of the cardiac cycle, this does not always happen in regional speckle tracking analysis. Some software rejects regional strain values if drift exceeds a certain level, but other vendors use drift compensation to force strain values to 0 at the end of the cardiac cycle. Radial strain is calculated as a change in transmural wall thickness during a cardiac cycle. Since the myocardium is incompressible, some vendors estimate radial strain from segmental area changes, assuming volume conservation [6]. Strain values may be represented as end-systolic strain or peak strain. These

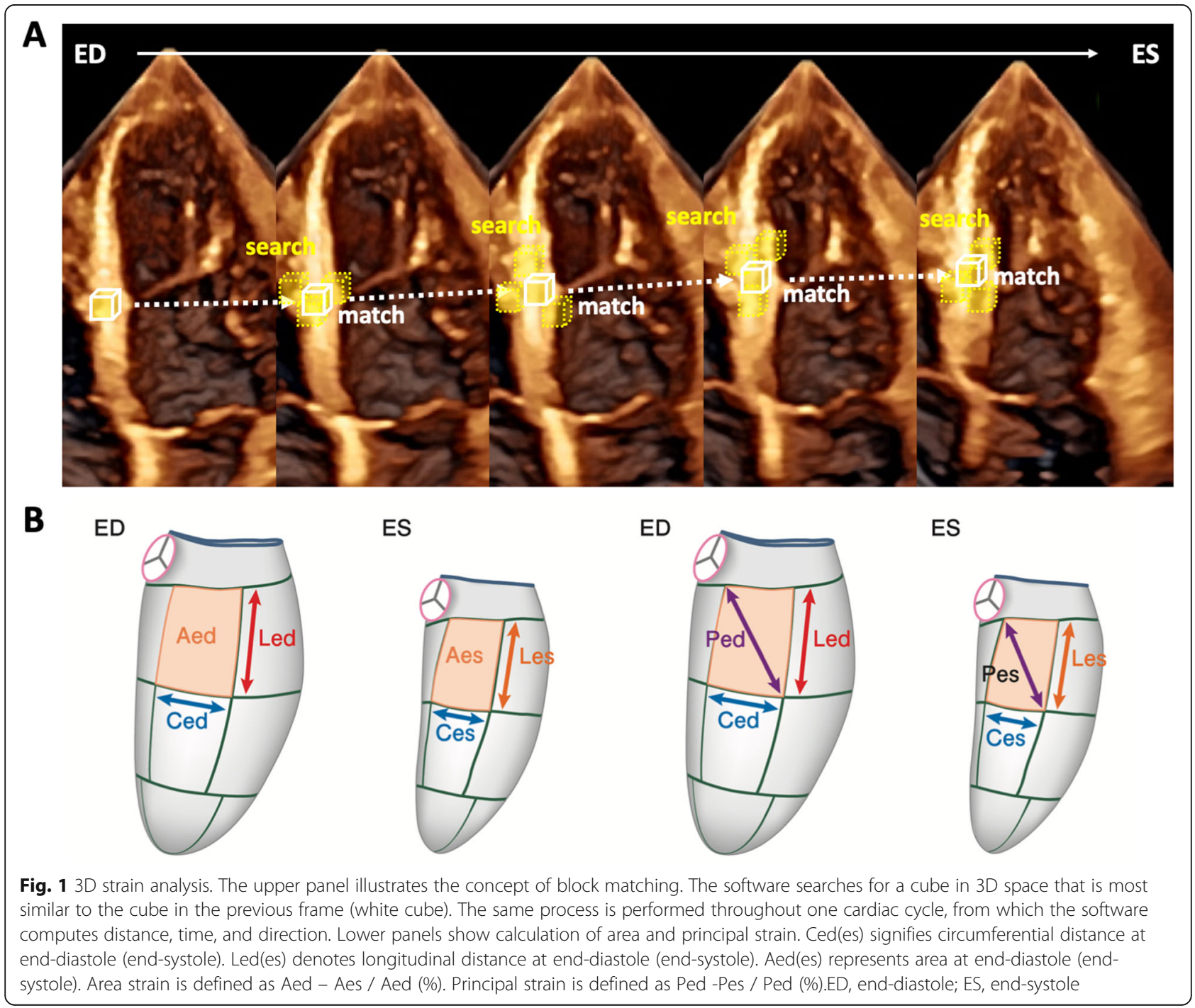


A
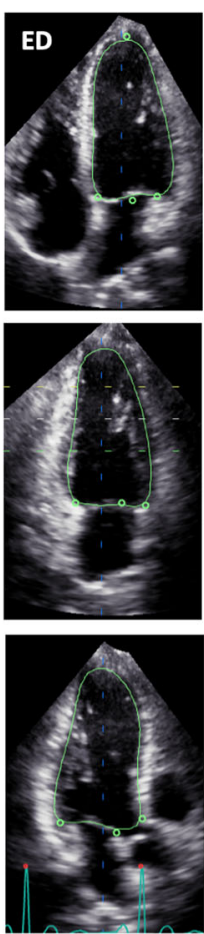

B
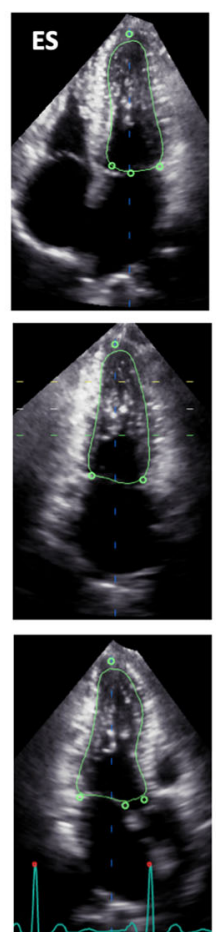

C
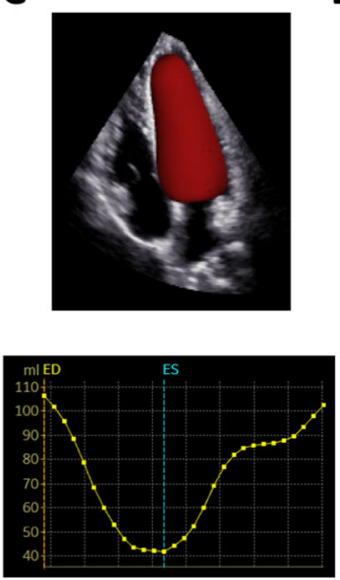

LV volume curve

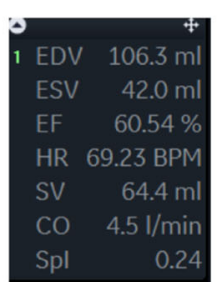

D
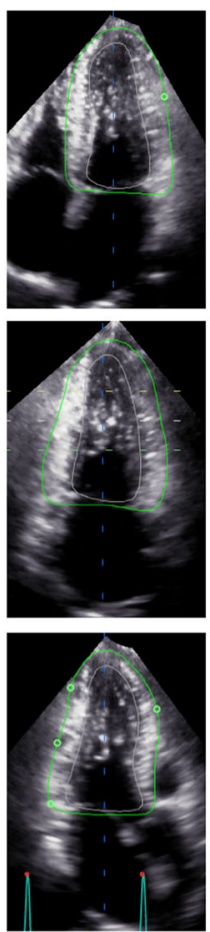

\section{E}

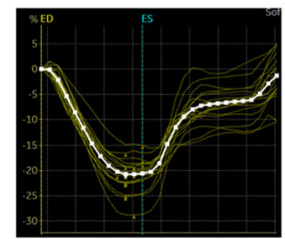

GLS: $-\mathbf{2 1 \%}$

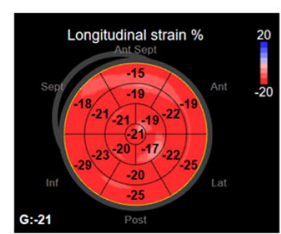

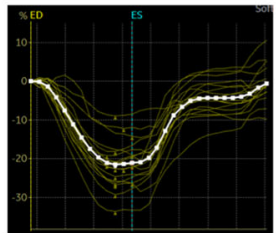

GCS: $-22 \%$

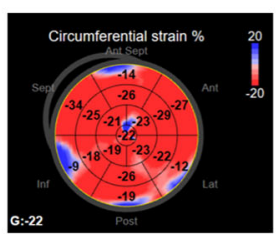

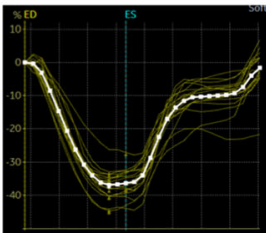

GAS: $-\mathbf{3 7 \%}$

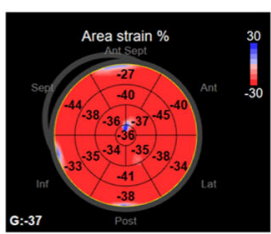

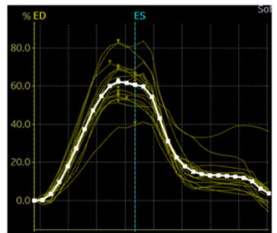

GRS: $\mathbf{6 2} \%$

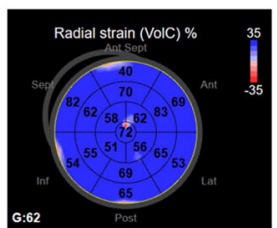

Fig. 2 3D strain analysis using GE software in a healthy subject. Left ventricular endocardial border determination in apical 4-, 2-, and long-axis views at end-diastole (a) and end-systole (b). Green lines indicate the endocardial border. The software performed LV border determination during one cardiac cycle, and the generated LV volume curve, from which LV end-diastolic volume, end-systolic volume, and LV ejection fraction (LVEF) were calculated. A beutel of the left ventricle is also shown (c). Epicardial border determination with manual editing identified the region of interest for subsequent speckle tracking (d). 3D regional and global longitudinal strain curves, a circumferential strain curve, an area strain curve, a radial strain curve, and a bull's eye map of corresponding regional strains (e), generated with 3D speckle tracking analysis. CO, cardiac output; ED, end-diastole; EDV, end-diastolic volume; EF, ejection fraction; ES, end-systole; ESV, end-systolic volume; HR, heart rate; GAS, global area strain; GCS, global circumferential strain; GLS, global longitudinal strain; GRS, global radial strain; Spl, sphericity index; SV, stroke volume

differences result in inter-vendor variability of 3D strain values that are significant, even when $3 \mathrm{DE}$ images are acquired from the same subjects [8].

\section{Characteristics of 2D and 3D strain}

2D strain requires acquisition of multiple 2DE images, including three short-axis views to measure global circumferential strain (GCS) and global radial strain (GRS), and three apical views to measure global longitudinal strain (GLS), resulting in longer data acquisition times. For analysis of all strain components by $2 \mathrm{DE}$, adequate quality of both parasternal and apical images is necessary. However, temporal and spatial resolution are higher, and feasibility is usually high. There have been 
A
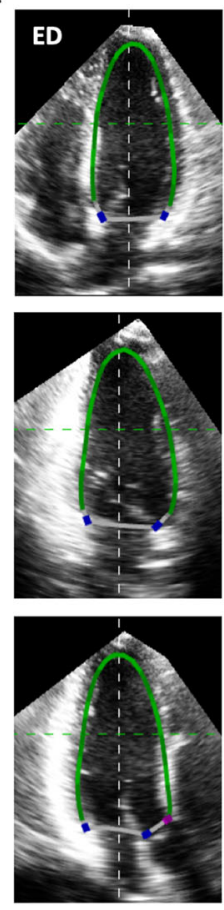

B
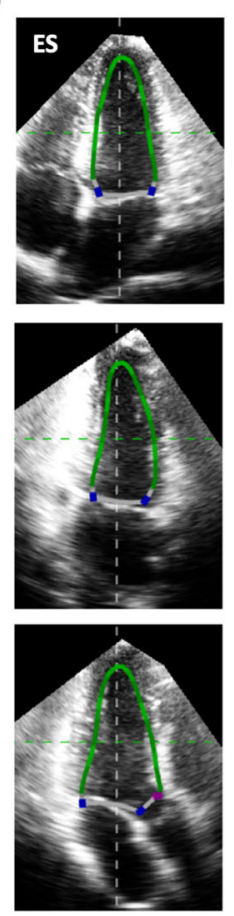

C
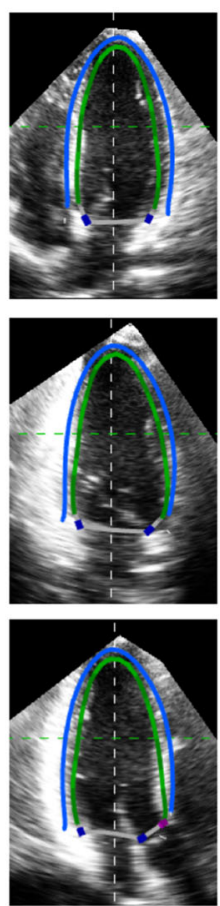

D
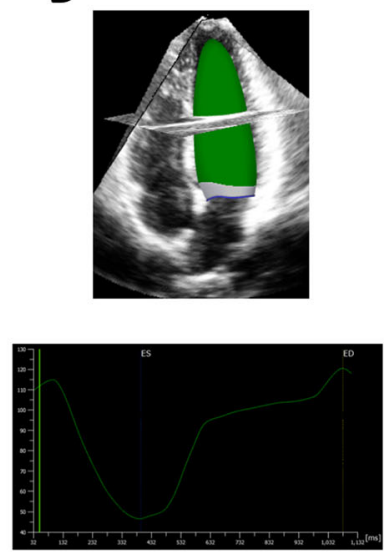

LV volume curve

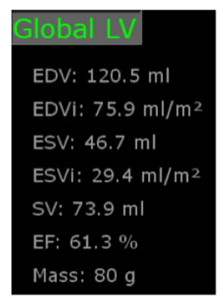

E

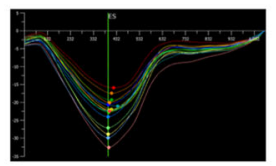

GLS: $-\mathbf{2 3 . 0 \%}$

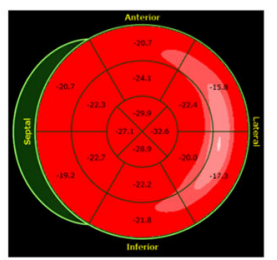

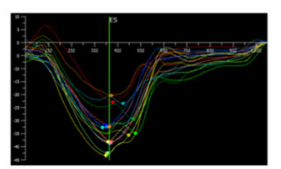

GCS: $-32.7 \%$

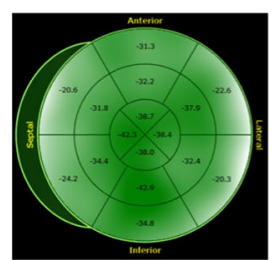

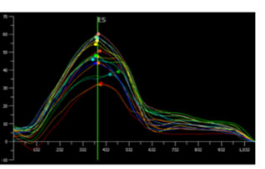

GRS: $46.8 \%$

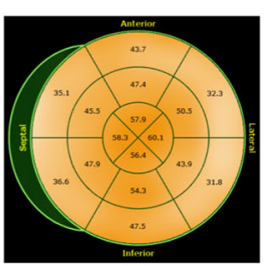

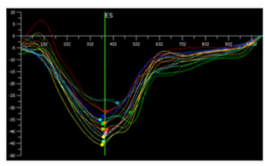

G3DS: $-36.7 \%$

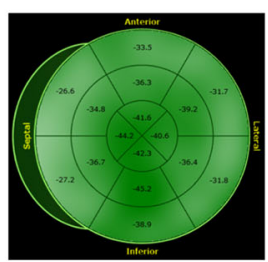

Fig. 3 3D strain analysis using TomTec software in a healthy subject. Left ventricular endocardial border determination on the apical 4-, 2-, and long-axis views at end-diastole (a) and end-systole (b). Manual epicardial border determination resulting in LV mass analysis (c). Green lines indicate the endocardial border, and blue lines indicate the epicardial border. The software performed 3D speckle tracking analysis on the endocardial border, generating an LV volume curve, from which LV end-diastolic volume, end-systolic volume, and LV ejection fraction (LVEF) were calculated $(\mathbf{d})$. The software also provided 3D regional and global longitudinal strain curves, a circumferential strain curve, a radial strain curve, and a 3D principal strain curve. Corresponding bull's eye maps were also provided (e). ED(S)Vi, left ventricular end-diastolic (end-systolic) volume index; G3DS, global principal strain. Other abbreviations are the same as in Fig. 2

several validation studies, and normal 2D global strain values have been reported from various large-scale studies [9-12]. Since 2D strain analysis is performed on a fixed 2DE cutting plane, some speckles or features may be lost in the 2DE imaging plane during a cardiac cycle, due to out-of-plane or twisting motion of the left ventricle [13].

In contrast, only a single apical acquisition is required for 3D strain analysis, resulting in shorter acquisition times and the opportunity to measure all 3D strain components from a single cardiac cycle. 3D strain measurements are not impacted by out-of-plane and twisting motion. However, 3D strain suffers from lower temporal and spatial resolution, which adversely affects tracking reliability. Multi-beat acquisition sometimes produces a stitching artifact between sub-volumes, which results in inaccurate speckle tracking analysis.

\section{Validation of 3D strain}

Reliability and accuracy of 3D strain measurements have been validated in several studies (Table 1) [14-18]. First, 
A
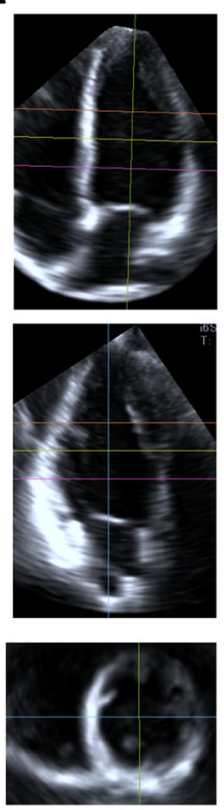

B
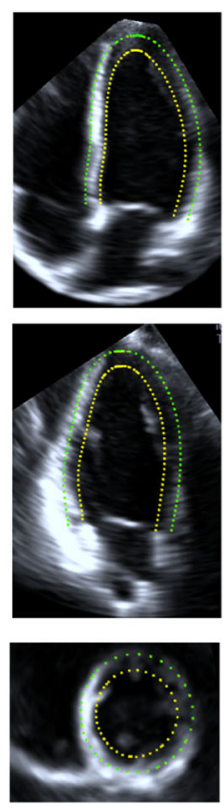

C
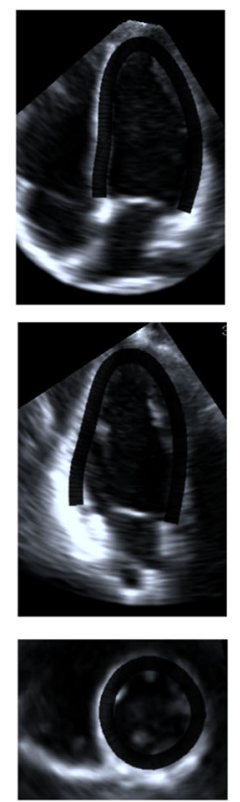

D
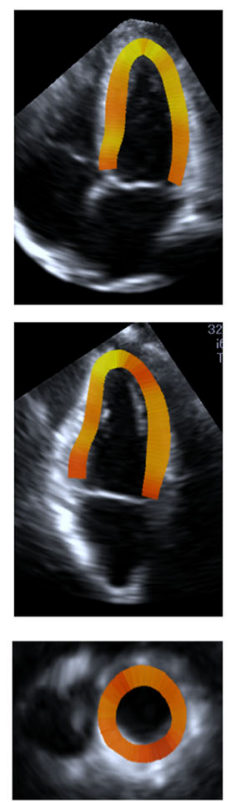

E
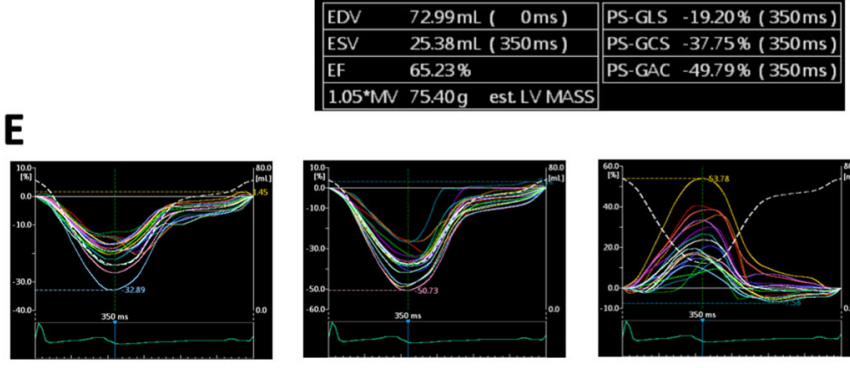

GLS: $-19.2 \%$

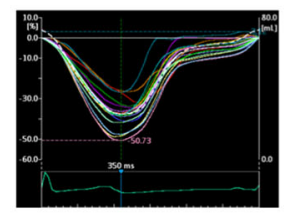

GCS: $-\mathbf{3 7 . 8} \%$
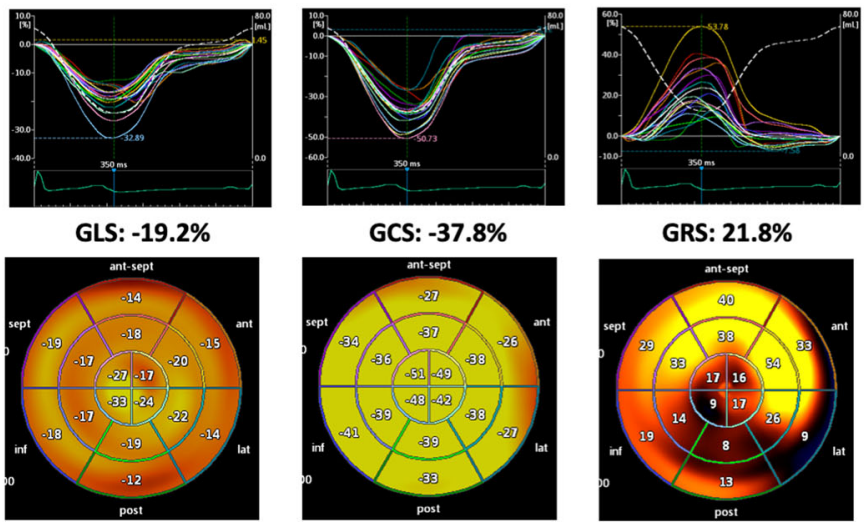

GRS: $\mathbf{2 1 . 8 \%}$
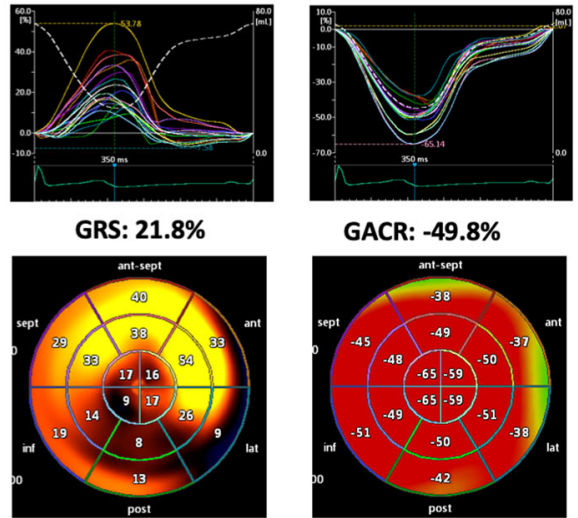

GACR: $\mathbf{- 4 9 . 8 \%}$

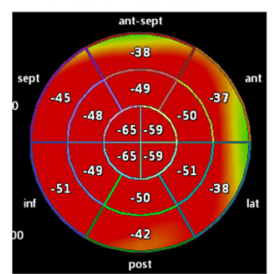

Fig. 4 3D strain analysis using Canon software in a healthy subject. Apical and short axis views extracted from the 3DE dataset (a). The software automatically determined the region of interest (b), and performed 3D speckle tracking analysis, generating a color-coded strain map at enddiastole (c) and end-systole (d). In addition to LV volumes and LVEF, the software provided regional strain curves and bull's eye map of longitudinal strain, circumferential strain, radial strain, and area change ratio (e). GACR, global area change ratio; MV, myocardial volume; PS, peak systolic. Other abbreviations are the same in Fig. 2

the accuracy of regional longitudinal, circumferential, and radial strain measurements was determined in experimental studies under different loading conditions, using sonomicrometry data as a reference [14]. There is good agreement between 3D regional strain measurements and corresponding values acquired using sonomicrometry. The best results have been observed in circumferential strain. The same authors subsequently reported that endocardial area strain correlated strongly with sonomicrometry data [15]. Area strain values differed significantly with baseline, pharmacologic stress, and acute ischemia, whereas there were no differences in longitudinal and circumferential strains at baseline or with propranolol infusion or dobutamine infusion, indicating that area strain is a more sensitive parameter than longitudinal or circumferential strain for detecting subtle changes in LV deformation. Other authors applied 3D strain analysis in humans to validate its accuracy. However, it is important to note that there is no true "gold standard" for 3D myocardial mechanics [19]. Instead 
Table 1 Validation studies for 3D strain

\begin{tabular}{|c|c|c|c|c|c|c|c|c|c|c|}
\hline \multicolumn{11}{|l|}{ Experimental studies } \\
\hline Author Year (Ref.\#) & Vendor & Materials & Reference & \multicolumn{2}{|c|}{$3 \mathrm{D}$ regional $\mathrm{LS}$} & \multicolumn{2}{|c|}{$3 \mathrm{D}$ regional $\mathrm{CS}$} & \multicolumn{2}{|c|}{$3 \mathrm{D}$ regional $\mathrm{RS}$} & $3 \mathrm{D}$ regional $\mathrm{AS}$ \\
\hline Seo 2009 [14] & Toshiba & Sheep & Sonomicrometry & \multicolumn{2}{|l|}{$\begin{array}{l}r=0.89 \\
p<0.001\end{array}$} & \multicolumn{2}{|l|}{$\begin{array}{l}r=0.90 \\
p<0.001\end{array}$} & \multicolumn{2}{|l|}{$\begin{array}{l}r=0.84 \\
p<0.001\end{array}$} & NA \\
\hline Seo 2011 [15] & Toshiba & Sheep & Sonomicrometry & \multicolumn{2}{|l|}{ NA } & NA & & \multicolumn{2}{|l|}{ NA } & $\begin{array}{l}r=0.87 \\
p<0.001\end{array}$ \\
\hline \multicolumn{11}{|l|}{ Human studies } \\
\hline Author Year (Ref.\#) & Vendor & Subjects & Reference & 3D GLS & 3D GCS & 3D GRS & 3D GAS & 2D GLS & 2D GCS & 2D GRS \\
\hline Kleijn 2012 [16] & Toshiba & Volunteer & CMR tagging & NA & $\begin{array}{l}r=0.80 \\
p: N A\end{array}$ & NA & NA & NA & NA & NA \\
\hline Luis 2014 [17] & GE & Patient & 2D LVEF & $\begin{array}{l}r=0.74 \\
p<0.001\end{array}$ & $\begin{array}{l}r=0.89 \\
p<0.001\end{array}$ & $\begin{array}{l}r=0.86 \\
p<0.001\end{array}$ & $\begin{array}{l}r=0.87 \\
p<0.001\end{array}$ & $\begin{array}{l}r=0.86 \\
p<0.001\end{array}$ & $\begin{array}{l}r=0.82 \\
p<0.001\end{array}$ & $\begin{array}{l}r=0.67 \\
p<0.001\end{array}$ \\
\hline Luis 2014 [17] & GE & Patient & 3D LVEF & $\begin{array}{l}r=0.75 \\
p<0.001\end{array}$ & $\begin{array}{l}r=0.89 \\
p<0.001\end{array}$ & $\begin{array}{l}r=0.87 \\
p<0.001\end{array}$ & $\begin{array}{l}r=0.88 \\
p<0.001\end{array}$ & $\begin{array}{l}r=0.86 \\
p<0.001\end{array}$ & $\begin{array}{l}r=0.84 \\
p<0.001\end{array}$ & $\begin{array}{l}r=0.64 \\
p<0.001\end{array}$ \\
\hline Obokata 2016 [18] & TomTec & Patient & CMR feature tracking & $\begin{array}{l}r=0.87 \\
p<0.001\end{array}$ & $\begin{array}{l}r=0.88 \\
p<0.001\end{array}$ & $\begin{array}{l}r=0.82 \\
p<0.001\end{array}$ & NA & $\begin{array}{l}r=0.83 \\
p<0.001\end{array}$ & $\begin{array}{l}r=0.90 \\
p<0.001\end{array}$ & $\begin{array}{l}r=0.69 \\
p<0.001\end{array}$ \\
\hline
\end{tabular}

AS area strain, CMR cardiac magnetic resonance, CS circumferential strain, GAS global area strain, GCS global circumferential strain, GLS global longitudinal strain, GRS global radial strain, LS longitudinal strain, LVEF left ventricular ejection fraction, NA not available, $R S$ radial strain

they employed surrogates, such as cardiac magnetic resonance myocardial tagging [16], feature tracking [18], or 2DE/3DE-derived LVEF [17].

\section{Feasibility of 3D strain}

The main impediment to acceptance of $3 \mathrm{D}$ strain is the lack of proof that it is truly superior to 2D strain for clinical use, beyond its theoretical advantages, resulting in its use mainly for research. A recent European Association of Cardiovascular Imaging (EACVI) survey from 96 echo laboratories in 22 European countries revealed that only $32 \%$ of European laboratories routinely use transthoracic 3DE, mainly due to limitations in image quality and operator dependency [20]. We performed a meta-analysis concerning the feasibility of $2 \mathrm{D}$ and $3 \mathrm{D}$ GLS in studies with sample sizes $>100$ patients [21-29]. Feasibility of 3D GLS was 85\% (95\% confidence interval (CI): 79 to $89 \%$ ). Corresponding values of 2D GLS were 91\% (95\% CI: 88 to $93 \%$ ). If we compared feasibility of 3D GLS among different ethnicities, values were 91\% (95\% CI: 84 to 95\%) in Asians, 81\% (95\% CI: 71 to $88 \%$ ) in Europeans, and 73\% (95\% CI: 65 to 80\%) in American patients. These results showed that feasibility of 3D GLS is lower than that of $2 \mathrm{D}$ GLS, and that feasibility is better in Asian patients than in American or European patients. However, there could be a selection bias, since some studies only selected patients with adequate 2DE image quality [23-25], and patients with poor 2DE image quality (the authors did not mention the number of these patients in the manuscripts) were excluded before strain analysis. Thus, actual feasibility of $2 \mathrm{D} / 3 \mathrm{D}$ strain in consecutive series of patients could be much lower than the observed results. All published studies came from echocardiographic laboratories where physicians and sonographers were thoroughly familiar with 3DE data acquisition and analysis. Thus, the results may not be generally applicable.

\section{Direct comparisons of 2D and 3D strain values}

We performed a meta-analysis to compare global 2D and $3 \mathrm{D}$ strain values using the same ultrasound vendor's 2D and 3D strain software. We selected only publications in which 2D GCS/GRS were measured using three short-axis views, and 2D GLS was measured with three apical views. We found 3846 paired comparisons of GLS between $2 \mathrm{DE}$ and $3 \mathrm{DE}$ in 36 publications using one of the three vendors (GE Healthcare, TomTec Imaging Systems, Toshiba Medical Systems) [13, 17, 18, 21-23, 25$28,30-55]$. The mean value of 3D GLS was significantly lower than that of $2 \mathrm{D}$ GLS, with a mean bias of $1.4 \%$ (Fig. 5). The pooled mean value of 3D GLS for GE and Toshiba was significantly lower than that of 2D GLS. However, there were no significant differences when using TomTec software. Regarding GCS, there were no statistically significant differences between 3D GCS and 2D GCS in 1894 paired comparisons [13, 18, 23, 25, 26, 30, 35-37, 40-43, 48, 50, 56]. Vendor analysis showed that 3D GCS was significantly smaller than 2D GCS when GE analytical software was used, but 3D GCS was significantly larger than 2D GCS when we used Toshiba or TomTec software. Finally, there were no significant differences between 3D GRS and 2D GRS in 1778 paired comparisons from 14 studies [18, 23, 25, 26, 30, 36, 37, $40-43,48,56,57]$. Although software from all three vendors yielded no differences in GRS between the two techniques, results in each publication showed different trends, such that 2D GRS was larger than 3D GRS in some studies $[25,26,42,43]$ and 2D GRS was smaller 


\begin{tabular}{|c|c|c|c|c|c|}
\hline & & Number of Subjects & Mean Difference (MD) & $M D(\%)$ & $95 \% \mathrm{Cl}$ \\
\hline & GE & 3005 & $\phi$ & -1.78 & $(-2.22 ;-1.34)$ \\
\hline \multirow[t]{5}{*}{ vendor } & TomTec & 386 & $=$ & 1.23 & $(-1.83 ; 4.29)$ \\
\hline & Toshiba & 455 & I & -1.35 & $(-2.51 ;-0.19)$ \\
\hline & \multirow[t]{3}{*}{ All } & \multirow[t]{3}{*}{3846} & $(\%)$ & \multirow[t]{3}{*}{-1.44} & \multirow[t]{3}{*}{$(-2.00 ;-0.88)$} \\
\hline & & & -5 & & \\
\hline & & & 3D GLS smaller $\quad$ 3D GLS larger & & \\
\hline & & Number of Subjects & Mean Difference (MD) & $M D(\%)$ & $95 \% \mathrm{Cl}$ \\
\hline & GE & 1363 & ol & -1.55 & $(-2.65 ;-0.44)$ \\
\hline \multirow[t]{5}{*}{ vendor } & TomTec & 184 & $\infty$ & 3.07 & $(1.18 ; 4.96)$ \\
\hline & Toshiba & 347 & $\infty$ & 4.18 & $(0.90 ; 7.46)$ \\
\hline & \multirow[t]{3}{*}{ All } & \multirow[t]{3}{*}{1894} & 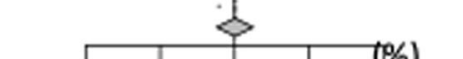 & \multirow[t]{3}{*}{0.02} & \multirow[t]{3}{*}{$(-1.20 ; 1.25)$} \\
\hline & & & $\begin{array}{lllll}-10 & -5 & 0 & 5 & 10\end{array}$ & & \\
\hline & & & 3D GCS smaller $\quad$ 3D GCS larger & & \\
\hline \multirow{2}{*}{ GRS } & & Number of Subjects & Mean Difference (MD) & $M D(\%)$ & $95 \% \mathrm{Cl}$ \\
\hline & GE & 1325 & & 1.61 & $(-1.63 ; 4.85)$ \\
\hline \multirow[t]{6}{*}{ vendor } & TomTec & 182 & & 1.42 & $(-2.58 ; 5.43)$ \\
\hline & Toshiba & 271 & & 0.30 & $(-3.34 ; 3.94)$ \\
\hline & All & 1778 & $\Leftrightarrow$ & 1.41 & $(-1.04 ; 3.87)$ \\
\hline & & & (\%) & & \\
\hline & & & $\begin{array}{lllll}-20 & -10 & 0 & 10 & 20\end{array}$ & & \\
\hline & & & 3D GRS smaller $\quad$ 3D GRS larger & & \\
\hline
\end{tabular}

than 3D GRS in others [23, 36, 37, 41, 56]. These results showed that differences in global strain between 2DE and $3 \mathrm{DE}$ vary according to the ultrasound vendor. Thus, 2D and 3D strain are not interchangeable, and we need vendor-dependent reference values of 3D strain.

\section{Reference values for 3D GLS}

Truong et al. [58] recently performed meta-analysis to determine normal ranges of LV 3D GLS, 3D GCS, 3D GRS, and 3D GAS in 2346 subjects from 32 studies. The authors reported that the mean value of 3D GLS was $19.1 \%$, ranging from 15.8 to $23.4 \%$ among the studies. However, the majority of selected studies had small sample sizes $(n=20-50)$, and the authors were forced to exclude one large study because median and interquartile range were presented in the manuscript, rather than means \pm standard deviations [59]. When we searched publications in which at least 100 healthy subjects were evaluated, there were seven independent datasets from six publications (Table 2) [59-64]. Overall, the mean value of 3D GLS was 18.1\% (95\% CI: 16.1 to $20.1 \%$ ). Mean values of 3D GLS ranged from 15.2 to $21.0 \%$ among the studies, and if we defined the lower limit of normal (LLN) as the mean - 1.96SD, LLN ranged from 11.1 to $15.9 \%$. The mean value of 3D GLS in male subjects $(n=696)$ was $18.4 \%$ (95\% CI: 16.5 to $20.3 \%$ ) in four studies that addressed gender-based strain analysis [59, $60,62,63]$. The corresponding value in female subjects ( $n=818$ ) was $19.8 \%$ (95\% CI: 17.7 to $21.8 \%)$. It is interesting that 3D GLS in female subjects was consistently and significantly higher than in male subjects, irrespective of the software used for the analysis, with a mean bias of $1.3 \%$ (95\% CI: 0.9 to $1.7 \%$ ). This finding suggests the need for establishment of gender-dependent reference values. Finally, as in a previous 2D GLS study [12], there were inter-vendor differences in 3D GLS reference 
Table 2 Reference range of 3D global longitudinal strain from six large studies

\begin{tabular}{|c|c|c|c|c|c|c|c|c|c|c|c|}
\hline $\begin{array}{l}\text { Author } \\
\text { year } \\
\text { (Ref.\#) }\end{array}$ & $n$ & Race & Vendor & Tracking & Mean \pm SD & $\begin{array}{l}\text { LLN (Overall) } \\
\text { (mean-1.96SD) }\end{array}$ & $\begin{array}{l}\text { Mean } \pm S D \\
\text { male }\end{array}$ & $\begin{array}{l}\text { Mean } \pm \text { SD } \\
\text { female }\end{array}$ & $\begin{array}{l}P \text { (male } \\
\text { vs. } \\
\text { female) }\end{array}$ & $\begin{array}{l}\text { LLN (Male) } \\
\text { (mean- } \\
1.96 S D \text { ) }\end{array}$ & $\begin{array}{l}\text { LLN (Female) } \\
\text { (mean- } \\
1.96 \mathrm{SD} \text { ) }\end{array}$ \\
\hline $\begin{array}{l}\text { Kaku } \\
2014 \text { [59] }\end{array}$ & 241 & $\begin{array}{l}\text { Japanese/ } \\
\text { American }\end{array}$ & TomTec & Subendocardial & $19.6 \pm 3.1 \%$ & $13.5 \%$ & $18.7 \pm 2.8 \%$ & $20.6 \pm 3.1 \%$ & $<0.001$ & $13.2 \%$ & $14.5 \%$ \\
\hline $\begin{array}{l}\text { Xia } 2014 \\
{[60]}\end{array}$ & 153 & Chinese & Toshiba & Full myocardial & $15.2 \pm 0.8 \%$ & $13.6 \%$ & NA & NA & NA & NA & NA \\
\hline $\begin{array}{l}\text { Muraru } \\
2014 \text { [58] }\end{array}$ & 265 & European & GE & Full myocardial & $18.7 \pm 2.6 \%$ & $13.5 \%$ & $17.8 \pm 2.4 \%$ & $19.4 \pm 2.6 \%$ & $<0.001$ & $13.0 \%$ & $14.2 \%$ \\
\hline $\begin{array}{l}\text { Muraru } \\
2014 \text { [58] }\end{array}$ & 265 & European & TomTec & Subendocardial & $20.4 \pm 3.8 \%$ & $12.8 \%$ & $19.5 \pm 3.8 \%$ & $21.1 \pm 3.6 \%$ & $<0.001$ & $11.9 \%$ & $13.9 \%$ \\
\hline $\begin{array}{l}\text { Kleijn } \\
2015 \text { [61] }\end{array}$ & 303 & $\begin{array}{l}\text { European/ } \\
\text { American }\end{array}$ & Toshiba & Full myocardial & $15.9 \pm 2.4 \%$ & $11.2 \%$ & $15.5 \pm 2.4 \%$ & $16.3 \pm 2.3 \%$ & 0.003 & $10.8 \%$ & $11.8 \%$ \\
\hline $\begin{array}{l}\text { Bernard } \\
2017 \text { [62] }\end{array}$ & 440 & European & TomTec & Subendocardial & $21.0 \pm 2.6 \%$ & $15.9 \%$ & $20.4 \pm 2.7 \%$ & $21.4 \pm 2.4 \%$ & $<0.001$ & $15.1 \%$ & $16.7 \%$ \\
\hline $\begin{array}{l}\text { Kovacs } \\
2019 \text { [63] }\end{array}$ & 178 & European & Toshiba & Full myocardial & $16.1 \pm 2.5 \%$ & $11.1 \%$ & NA & NA & NA & NA & NA \\
\hline
\end{tabular}

LLN lower limit of normal, NA not available, SD standard deviation

Other abbreviations are the same in Table 1

values. The lowest values were observed when Toshiba software $(15.4 \pm 1.4 \%, n=634)$ was used, followed by GE software $(18.7 \pm 2.6 \%, n=265)$. The highest values were obtained with TomTec software $(20.6 \pm 3.0 \%, n=946)$. This is partly because ultrasound vendors use different ROIs for speckle tracking (both TomTec and Toshiba software use subendocardial tracking [14], but GE software uses full myocardial tracking). Different 3D dataset characteristics in each vendor is another cause of discrepancy [65]. The World Alliance Societies of Echocardiography Normal Values Study plans to address whether racial differences in 3D strain are observed [11].

\section{Clinical applications of 3D strain}

Since clinical applications of 3D strain are still limited, we focus here on its usefulness in several clinical scenarios.

\section{Ischemic heart disease}

Even in patients who had received successful primary percutaneous coronary intervention after acute myocardial infarction, when LV adverse remodeling occurs, it is associated with poor outcomes; thus, for reliable, accurate assessment, it is of paramount importance to stratify high risk patients after the intervention. Infarct size negatively affects LV function; thus, it is a major determinant of LV adverse remodeling. 2D and 3D deformation parameters, which reflect regional and global LV function, may reliably evaluate infarct size and transmural extent of myocardial infarction. Several studies have demonstrated the clinical usefulness of 3D strain analysis in patients with acute or recent myocardial infarction, who underwent primary percutaneous coronary intervention $[28,31,34,50,66-70]$. Some studies addressed the utility of 3D strain for predicting LV adverse remodeling (defined as an increase in LV end-diastolic volume $\geq 15 \%$ or $20 \%$ ) or LV functional recovery (defined as an improvement $\geq 5 \%$ of LVEF) during the chronic phase (Table 3) [28, 31, 34, 50, 66-69]. 3D global strain analysis was possible in $>80 \%$ of study subjects. All studies revealed that 3D global strain, especially 3D GLS and 3D GAS, predict LV adverse remodeling with moderate accuracy (57 to $75 \%$ ). Only one study compared predictive values of $2 \mathrm{D}$ and $3 \mathrm{D}$ global strain. It showed that 3D GLS was a significantly better predictor of LV adverse remodeling than 2D GLS, 3D GAS, or 3D GRS [28].

Since endocardial fibers are oriented longitudinally, and mid-myocardial fibers run circumferentially, preferential reduction of longitudinal strain and preserved circumferential strain could reflect the presence of subendocardial myocardial infarction, and reduction of both longitudinal and circumferential strains may represent transmural myocardial infarction. Other studies investigated the diagnostic value of 3D strain measurements for evaluating the transmurality of infarction, which was verified using cardiac magnetic resonance with late gadolinium enhancement (LGE) (subendocardial infarction, $0 \%$ to $\leq 50 \%$; transmural infarction, $>50 \%$ of the transmural extent of LGE) $[31,34,50,68,69]$. In contrast to the aforementioned theory, all 3D regional strain measurements differed significantly among segments with no myocardial infarction, segments with non-transmural infarction, and segments with transmural infarction. In addition, none of the studies unequivocally demonstrated that $3 \mathrm{D}$ regional strain is superior to 2D regional strain for evaluating transmurality of myocardial infarction.

The potential utility of 3D strain to determine myocardial infarct size has been also reported [31, 34, 68, 69]. Overall, there were modest correlations between 3D 


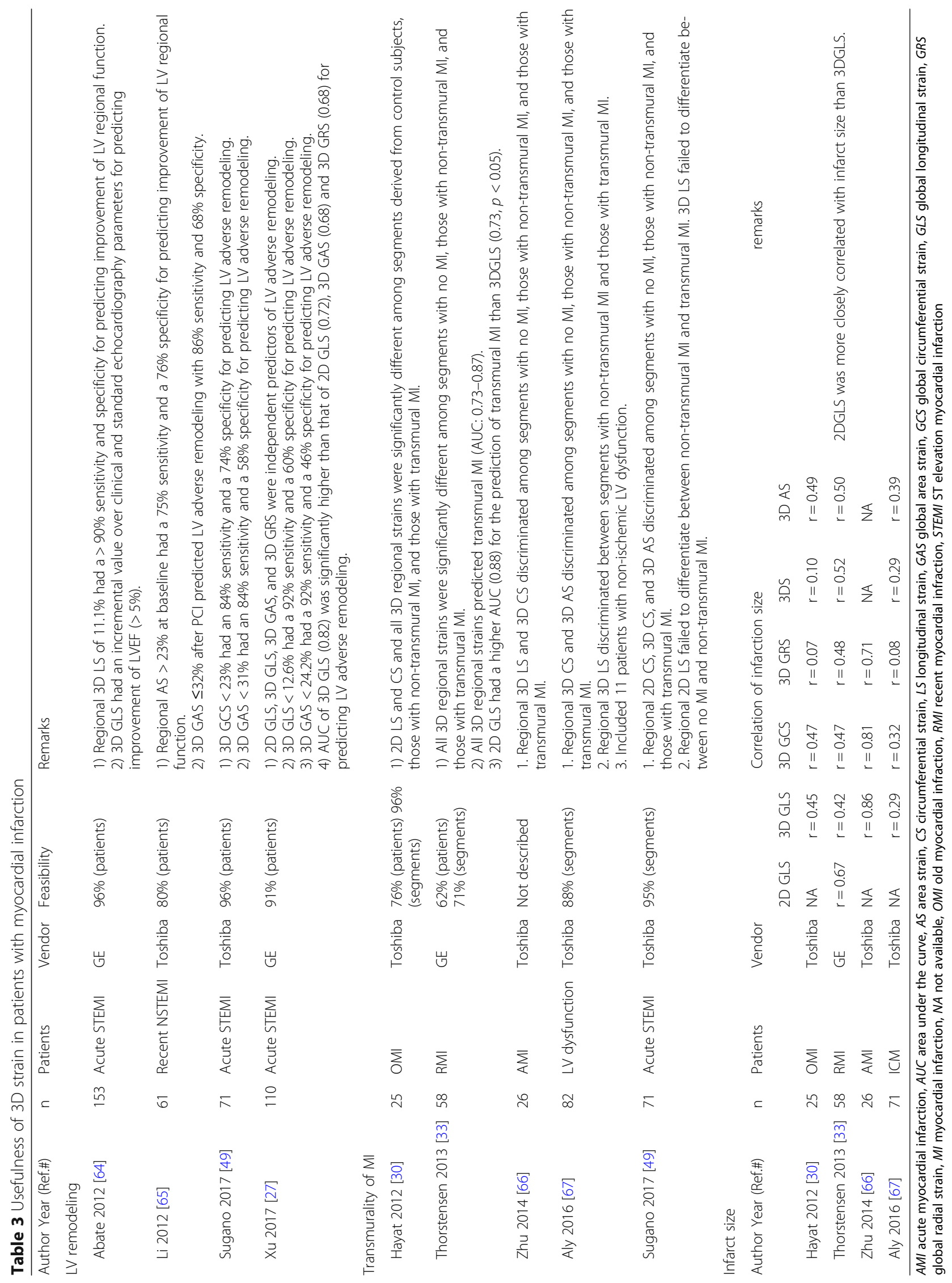


GLS/ 3D GCS and infarct size assessed by LGE using cardiac magnetic resonance imaging. A meta-analysis revealed that the $r$ value for the correlation between 3D GLS and the percentage of myocardial infarction size in four studies [31, 34, 68, 69] was only 0.55 (95\% CI: 0.19 to 0.78 ) with notable heterogeneity [70]. Pooled $\mathrm{r}$ values further decreased to 0.38 (95\% CI: 0.22 to 0.54 ) when one study that was a potential cause of heterogeneity was excluded from the analysis.

These results suggest that 3D global strain analysis may be useful to predict LV adverse remodeling. However, their diagnostic accuracy is modest at best. 3D regional strain measurement is not sufficiently sensitive to discriminate between subendocardial infarction and transmural infarction. 3D global strain values are not useful to determine infarct size. There are also no consistent findings to suggest that 3D strain is more useful than 2D strain. Further large-scale studies are required to determine whether 3D strain has some added value over 2D strain for evaluating patients with myocardial infarction after coronary intervention.

\section{Cardio-oncology}

As the development of tumor-targeted anticancer drugs allows cancer patients to live longer, cancer therapyrelated cardiac dysfunction and/or heart failure is becoming a major issue [71]. Although cardiac dysfunction in patients undergoing cancer treatment is complex with respect to treatment regimen, cardiotoxic anticancer drugs, age, and comorbidities, detection of subclinical myocardial dysfunction facilitates timely intervention and reduces the risk of adverse outcomes. 2D strain has proven useful to detect subclinical LV dysfunction in cancer patients [72]. Several studies have attempted to determine the clinical usefulness of 3D strain in cancer patients who had been treated with cardiotoxic anticancer drugs [27, 40, 54, 73-76]. All but one study showed a significant reduction of 3D global strain during and after cardiotoxic anticancer drugs, compared with baseline (Table 4). A significant reduction of 3D global strain was already observed at a timepoint when 2D LVEF and/or 2D global strains were still normal in some studies [73, 74]. Another study revealed that 3D LVEF and 3D global strains were associated with concurrent and subsequent changes in 2D LVEF [75]. However, there were no consistent findings that a specific 3D strain component is most robust for detecting subtle LV dysfunction. There were also very few articles that validated added value of $3 \mathrm{D}$ strain over $2 \mathrm{D}$ strain for predicting LV dysfunction [75]. Thus, 3D strain can predict subclinical LV dysfunction, but data were insufficient to conclude whether 3D strain is better than 2D strain.

Acquisition of good-quality echocardiographic images is a potential concern in breast cancer patients because patients often receive mastectomies and radiation therapy of the chest. A meta-analysis from seven studies (Table 4) revealed that feasibility of 3D strain measurements before and after treatment were 93\% (95\% CI: 85 to $97 \%$ ) and $92 \%$ (95\% CI:80 to $97 \%$ ), respectively. However, it is worth noting that patients with bad image quality were excluded in some studies [40,54]. In this regard, the results from Santoro and colleagues may represent the current feasibility of $2 \mathrm{D} / 3 \mathrm{D}$ strain measurements in prospectively enrolled breast cancer patients [27]. This study also showed that 2D GLS was better than 3D global strain for evaluating treatment course in breast cancer patients due to high feasibility and reasonable detection of subclinical LV dysfunction.

Only two studies investigated the prognostic value of $3 \mathrm{D}$ global strain to predict cancer therapy-related cardiac dysfunction and/or heart failure with moderate accuracy $(70$ and $73 \%)$ [54, 73]. Thus, further studies are required to verify whether $3 \mathrm{D}$ strain is better than $2 \mathrm{D}$ strain to predict outcomes. It is also necessary to investigate whether patient management guided by $3 \mathrm{D}$ LVEF and/or 3D strain is better than that guided by 2D LVEF and/or 2D strain to prevent heart failure in cancer patients.

\section{Subclinical LV dysfunction}

LV longitudinal functional impairment in patients with preserved LVEF is the first component that has been demonstrated using 2D strain analysis [1, 2]. 3D strain analysis has been performed to verify this concept in asymptomatic patients with normal LVEF who had comorbidities (hypertension, diabetes or collagen disease) $[6,36,37,44,49,52,56,77]$. Pooled analysis revealed that both 2D and 3D GLS in patients were consistently and significantly depressed compared with control subjects (Supplementary Figure 1). Thus, both 2D and 3D strain can detect subclinical LV dysfunction.

\section{Left ventricular hypertrophy}

LV hypertrophy (LVH) has been associated with increased cardiovascular death and all causes of death, independent of traditional risk factors [78]. The potential usefulness of $3 \mathrm{D}$ strain in patients with $\mathrm{LVH}$ is summarized in Table 5 [39, 47, 53, 79-83]. In patients with hypertension, Tadic et al. demonstrated that $2 \mathrm{D}$ and $3 \mathrm{D}$ global strain values differed among five types of LV geometry showing that the worst LV deformation parameters were observed in concentric $\mathrm{LVH}$ and dilated $\mathrm{LVH}$, even after adjusting anthropometric and hemodynamic parameters [39].

Both 3D GLS and GAS were consistently impaired irrespective of the severity of $\mathrm{LVH}$, but 3D GCS was preserved or even enhanced in patients with hypertrophic cardiomyopathy $[53,80,82]$. These results indicate that 
Nabeshima et al. Cardiovascular Ultrasound

(2020) 18:23

Page 11 of 21

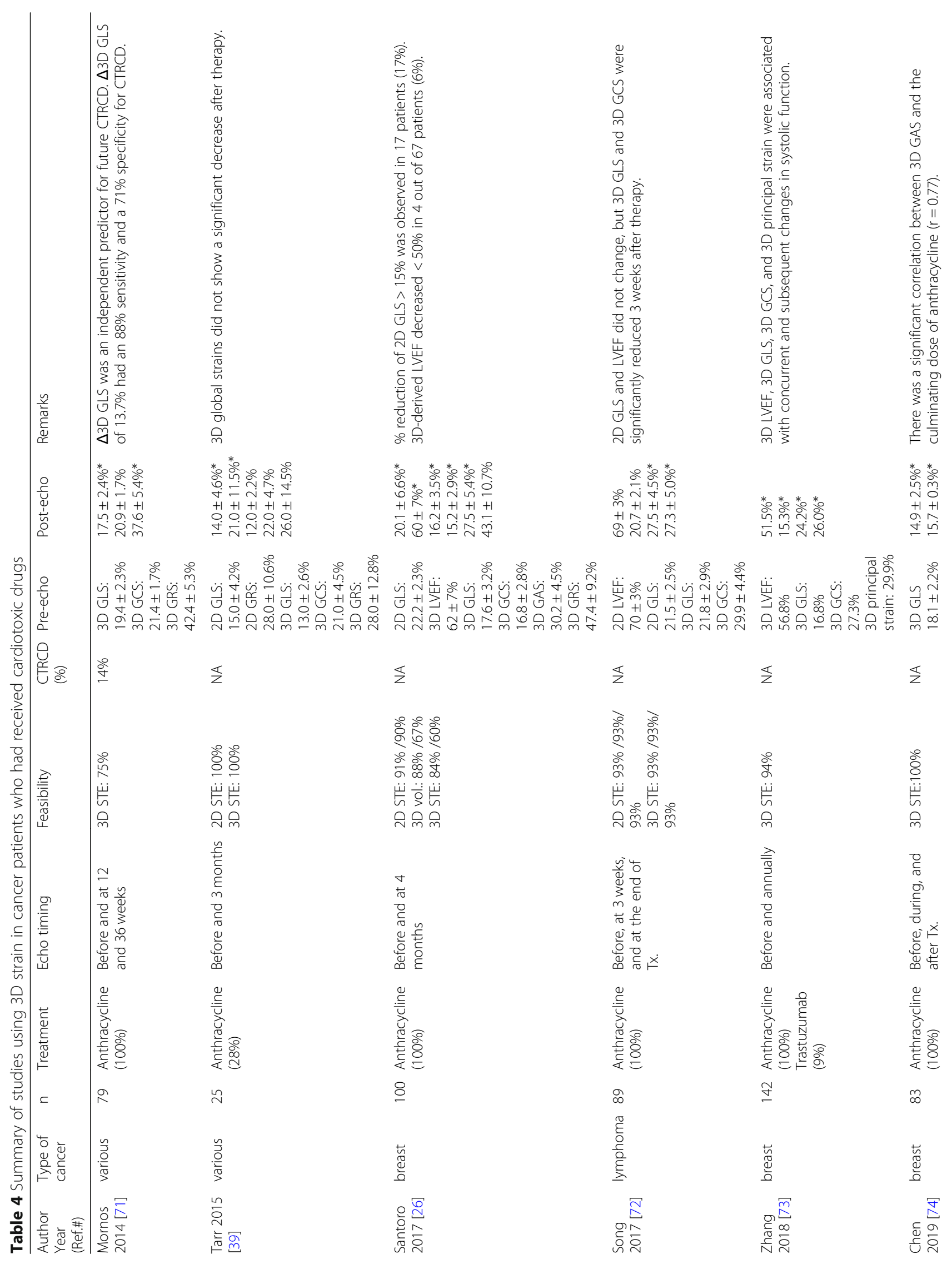


Nabeshima et al. Cardiovascular Ultrasound

(2020) $18: 23$

Page 12 of 21

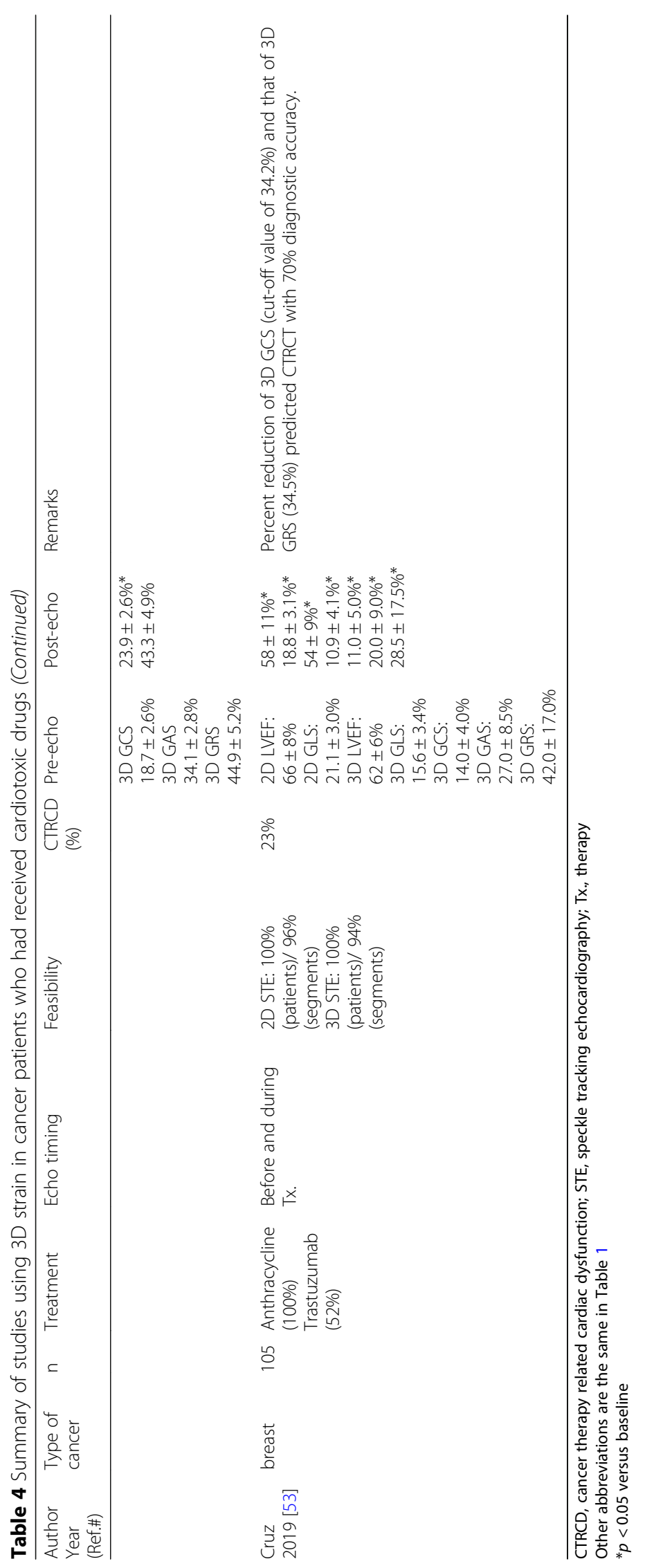


Table 5 Summary of studies using 3D strain in patients with LV hypertrophy

\begin{tabular}{|c|c|c|c|}
\hline $\begin{array}{l}\text { Author } \\
\text { Year (Ref \#) }\end{array}$ & $\begin{array}{l}\text { Type of disease } \\
\text { (number) }\end{array}$ & Purpose & Remarks \\
\hline $\begin{array}{l}\text { Baccouche } \\
2012[77]\end{array}$ & $\mathrm{CA}(n=12) / \mathrm{HCM}(n=12)$ & $\begin{array}{l}\text { To differentiate two } \\
\text { pathologies. }\end{array}$ & $\begin{array}{l}\text { 1) Basal LS, CS and RS were significantly reduced in } \\
\text { patients with CA compared with HCM. } \\
\text { 2) Regional strain values were irreversibly correlated } \\
\text { with LGE, and the best correlation was observed } \\
\text { between RS and LGE ( } r=-0.82 \text { ) }\end{array}$ \\
\hline $\begin{array}{l}\text { Aly } 2014 \\
{[78]}\end{array}$ & $\begin{array}{l}\text { HCM mutation carriers }(n=23) / \mathrm{HCM}(n=28) / \\
\text { control }(n=29)\end{array}$ & $\begin{array}{l}\text { To detect early changes } \\
\text { in myocardial mechanics } \\
\text { in HCM mutations. }\end{array}$ & $\begin{array}{l}\text { 1) There were no significant differences in } 3 D \text { global/ } \\
\text { regional strains between HCM mutations and control } \\
\text { subjects. } \\
\text { 2) } 3 D \text { global/regional LS and AS were significantly } \\
\text { impaired in HCM compared with HCM mutations. } \\
\text { 3) } 3 D \text { GCS and 3DGRS were not different between } \\
\text { HCM and HCM mutations. }\end{array}$ \\
\hline $\begin{array}{l}\text { Tadic } 2015 \\
{[38]}\end{array}$ & $\begin{array}{l}\text { HT with normal LV geometry }(n=85) / \text { concentric } \\
\text { LV remodeling }(n=28) / \text { eccentric nondilated LVH } \\
\text { (42) / concentric LVH }(n=30) / \text { dilated and } \\
\text { concentric-dilated LVH }(n=12)\end{array}$ & $\begin{array}{l}\text { To investigate LV } \\
\text { mechanics in HT with } \\
\text { different geometric } \\
\text { patterns }\end{array}$ & $\begin{array}{l}\text { 1) } 2 \mathrm{D} \text { and } 3 \mathrm{D} \text { global strains decreased normal } \\
\text { geometry, followed by concentric remodeling, } \\
\text { eccentric nondilated LVH, concentric LVH, dilated LVH } \\
\text { and concentric dilated LVH. } \\
\text { 2) Reduced } 2 \mathrm{D} \text { and } 3 \mathrm{D} \text { strains were associated with } \\
\text { concentric and dilated LVH patterns independent of } \\
\text { demographic and clinical parameters. }\end{array}$ \\
\hline $\begin{array}{l}\text { Urbano- } \\
\text { Moral } 2015 \\
{[79]}\end{array}$ & AL amyloidosis $(n=40)$ & $\begin{array}{l}\text { To detect cardiac } \\
\text { involvement. }\end{array}$ & $\begin{array}{l}\text { 1) } 3 D \text { GLS and GCS were significantly lower in } \\
\text { patients with cardiac involvement than those without } \\
\text { 2) Prominent reduction of LS/CS was observed in the } \\
\text { basal myocardium. }\end{array}$ \\
\hline $\begin{array}{l}\text { Voilliot } \\
2015 \text { [80] }\end{array}$ & $\mathrm{HCM}(n=40) /$ control $(n=53)$ & $\begin{array}{l}\text { To assess impact of } \\
\text { hypertrophy on strains. }\end{array}$ & $\begin{array}{l}\text { Compared to control subjects, } \\
\text { 1) } 3 D \text { GLS, GAS, and GRS were significantly lower in } \\
\text { HCM patients. } \\
\text { 2) No significant differences in 3D GCS were noted. } \\
\text { 3) } 3 D \text { regional LS/AS was significantly depressed } \\
\text { irrespective to the degree of hypertrophy. } \\
\text { 4) 3D regional CS was higher in no or mildly } \\
\text { hypertrophied segments. }\end{array}$ \\
\hline $\begin{array}{l}\text { Ternacle } \\
2017[52]\end{array}$ & $\begin{array}{l}\text { Athlete with moderate LVH }(n=25) / \text { Athlete } \\
\text { without LVH }(n=25) / \operatorname{HCM}(n=25) / \text { control }(n= \\
\text { 25) }\end{array}$ & $\begin{array}{l}\text { To differentiate patients } \\
\text { with HCM from athletes } \\
\text { with moderate } \mathrm{LVH} \text {. }\end{array}$ & $\begin{array}{l}\text { 1) } 2 D \text { GLS and } 3 D \text { GLS were significantly lower in } \\
\text { HCM than athletes with moderate LVH. } \\
\text { 2) } 2 D \text { LV dyssynchrony index (SD of time to peak LS } \\
\text { in } 16 \text { segment model) had a highest AUC for } \\
\text { identifying HCM in the presence of moderate LVH. } \\
\text { 3) } 3 D \text { GCS was not different between the two groups. }\end{array}$ \\
\hline $\begin{array}{l}\text { Cho } 2017 \\
{[46]}\end{array}$ & $\begin{array}{l}\text { Severe AS with normal LVEF }(\geq 55 \%, n=45) / \\
\text { control }(n=18)\end{array}$ & $\begin{array}{l}\text { To evaluate early } \\
\text { myocardial dysfunction }\end{array}$ & $\begin{array}{l}\text { 1) } 2 D \text { GLS and } 3 D \text { GLS were significantly impaired in } \\
\text { severe AS patients with increased LV wall thickness } \\
\text { compared with normal LV wall thickness. } \\
\text { 2) } 3 D G C S, G A S \text {, and GRS did not show any } \\
\text { differences between the two groups. }\end{array}$ \\
\hline $\begin{array}{l}\text { Pradel } \\
2019[81]\end{array}$ & AL amyloidosis $(n=58) /$ control $(n=21)$ & $\begin{array}{l}\text { To detect LV } \\
\text { dysfunction. }\end{array}$ & $\begin{array}{l}\text { 1) There were no significant differences in } 3 D \text { LVEF } \\
\text { and } 3 D \text { global strains between Mayo Clinic Stage I AL } \\
\text { amyloidosis and control subjects. } \\
\text { 2) } 3 D \text { LVEF and } 3 D \text { global strains decreased according } \\
\text { to the advanced Mayo Clinic stage. }\end{array}$ \\
\hline
\end{tabular}

AS aortic stenosis, CA cardiac amyloidosis, HCM hypertrophic cardiomyopathy, $H T$ hypertension, $L G E$ late gadolinium enhancement, $L V H$ left ventricular hypertrophy, $S D$ standard deviation

Other abbreviations are the same in Table 1

preservation of 3D GCS may be a compensatory mechanism for maintaining LVEF.

3D strains are also reportedly impaired in patients with cardiac amyloidosis $[79,83]$. Regional assessment of strain values has been reported in only one study [79]. Compared to hypertrophic cardiomyopathy, basal radial strain was remarkably reduced, but apical radial strain was preserved in patients with cardiac amyloidosis, and the findings were compatible to the apical sparing pattern observed using 2D longitudinal strain [84] (Fig. 6). Finally, there are still not enough data to validate whether $3 \mathrm{D}$ strain has added value over 2D strain in patients with LVH.

\section{Valvular heart disease}

$3 \mathrm{D}$ strain has been assessed in patients with valvular heart disease [26, 41, 47, 85-88]. Several authors analyzed 3D 


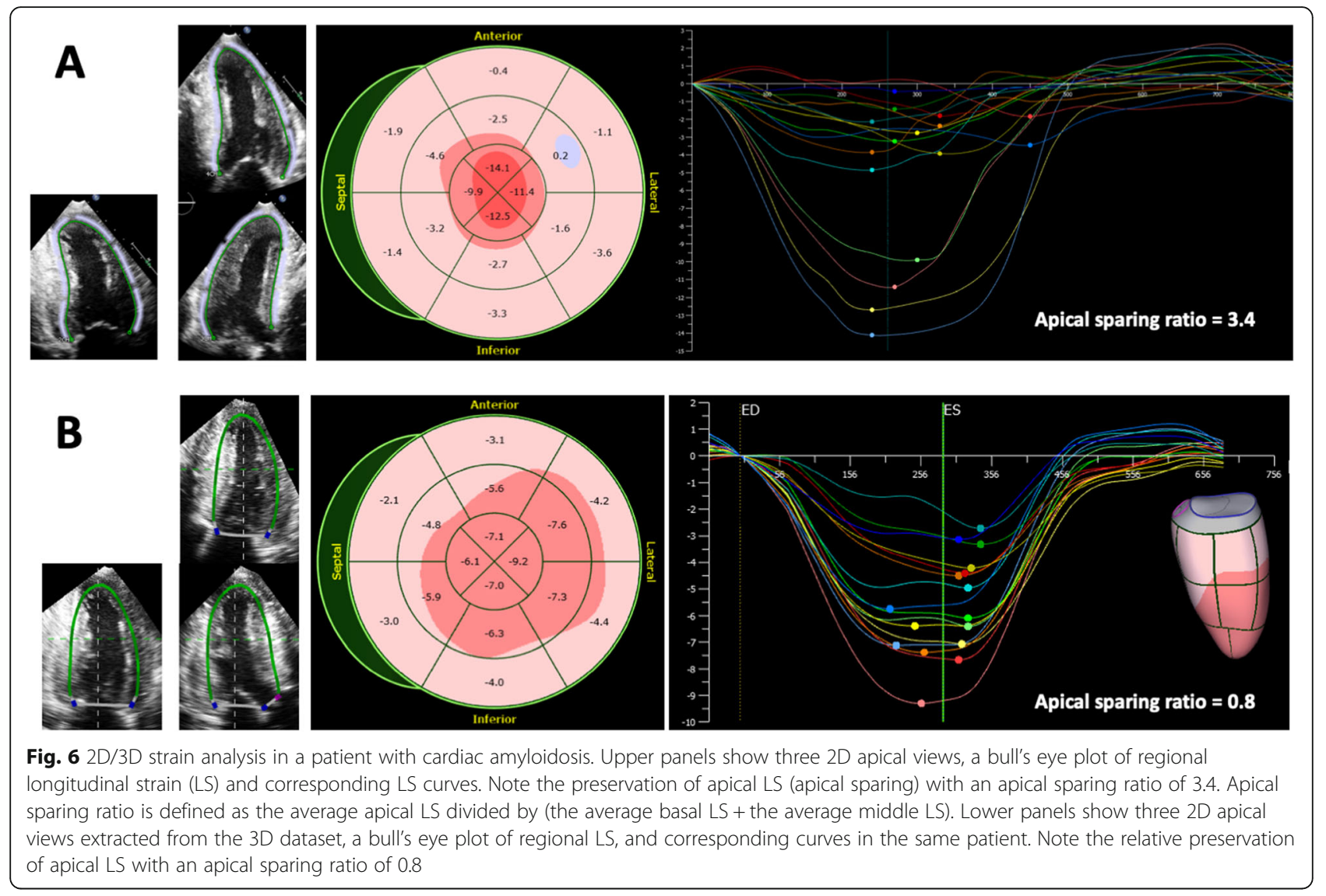

strain before and after transcatheter aortic valve replacement (TAVR) or MitraClip [41, 85, 87]. 2D and 3D GLS were significantly improved 6 months after TAVR in patients with severe aortic stenosis, and this beneficial trend was more obvious in patients whose baseline LVEF was more impaired, which reflects the presence of afterload mismatch [85]. All 3D global strains except 3D GRS were improved significantly 6 months after the MitraClip in patients with more than moderate mitral regurgitation [41]. The authors also noted that right ventricular dysfunction at baseline was associated with poor improvement of 3D global strains. The other study showed that 3D LV volumes, LVEF, and 2D GLS were not improved, but 3D GLS was improved 1 month after the MitraClip [87]. An impairment of 3D GLS with compensated augmentation of 3D GCS has been reported in asymptomatic patients with moderate or severe aortic regurgitation [88]. This compensating circumferential function could result in normal LVEF, a finding also reported in patients with hypertrophic cardiomyopathy [53, 80, 82].

\section{Cardiac resynchronization therapy}

Although echocardiographic assessment of LV mechanical dyssynchrony was expected to assist selection of optimal candidates for cardiac resynchronization therapy (CRT), because of the negative outcome of the PROSPECT trial, echocardiography was not recommended by current guidelines [89]. Several investigators have used 3D strain to evaluate LV dyssynchrony to predict CRT responders [90-94]. The authors measured time from onset of the QRS complex to peak strain, and determined the earliest and latest activation sites or created a new dyssynchrony index. However, it should be noted that time to peak strain does not reflect time to onset of mechanical contraction.

Seo et al. developed an activation imaging system using 3D area strain analysis which sought to quantify time from the QRS complex to the onset of regional deformation, and its reliability and accuracy has been validated against 3D voltage-mapping systems [95]. Activation imaging allows detection of the earliest activation site, subsequent propagation sequence, and latest activation. The same authors also demonstrated that the presence of a U-shaped propagation pattern, which was characterized as activation propagated from the mid septum, followed by the apex to the lateral or posterior wall, had a sensitivity of $88 \%$ and a specificity of $95 \%$ for predicting CRT volume responder $(\geq 15 \%$ reduction of LV end-systolic volume at 6 months 
after CRT) [96] (Fig. 7). A U-shaped propagation pattern was also associated with good outcomes after adjusting left bundle branch block or LV end-diastolic volume. Thus, activation imaging with 3D speckle tracking analysis has potential to visualize propagation of LV regional activation and to provide additional value for predicting outcomes in patients who are referred for CRT.

\section{Prognostic value}

Several studies investigated the prognostic value of 3D strain in myocardial infarction, hemodialysis, valvular heart disease, and a diverse variety of subjects $[24,26,48,86,97-$ 100] (Table 6). These studies all showed that 3D global strains were impaired in patients who had cardiac events, and reduction of $3 \mathrm{D}$ global strains was associated with poor outcomes. Reduction of 2D and 3D strains was attributed to myocardial fibrosis or inflammation [101]. Three of eight studies directly compared prognostic values between $2 \mathrm{D}$ GLS and 3D GLS, and all three studies showed that 3D GLS had superior prognostic value over 2D GLS [26, 99, 100]. Further studies are needed to validate whether 3D GLS is distinctly superior to 2D GLS for predicting future outcomes in specific cardiovascular pathologies.

\section{Novel techniques}

Multimodality imaging allows fusion imaging [102-104]. Mor-Avi and colleagues performed fusion imaging using computed tomography coronary angiography (CTCA) and 3D longitudinal strain $[103,104]$. Resting 3D regional longitudinal strain was color-coded to detect

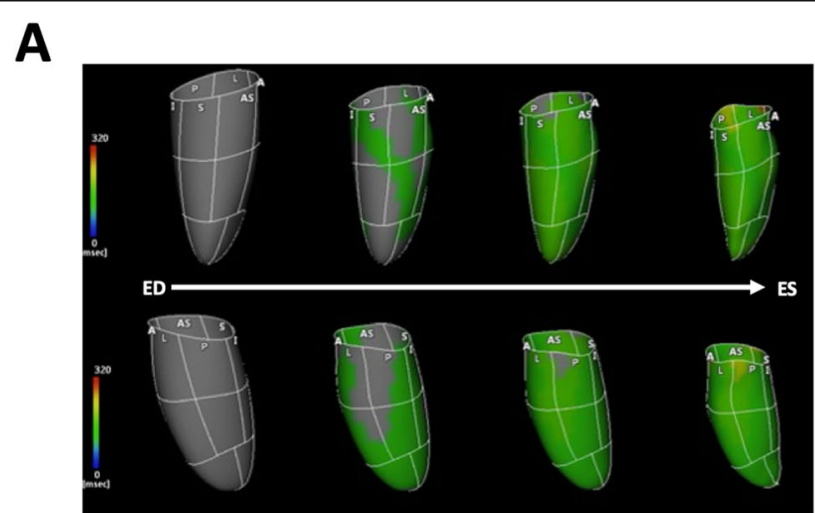

B

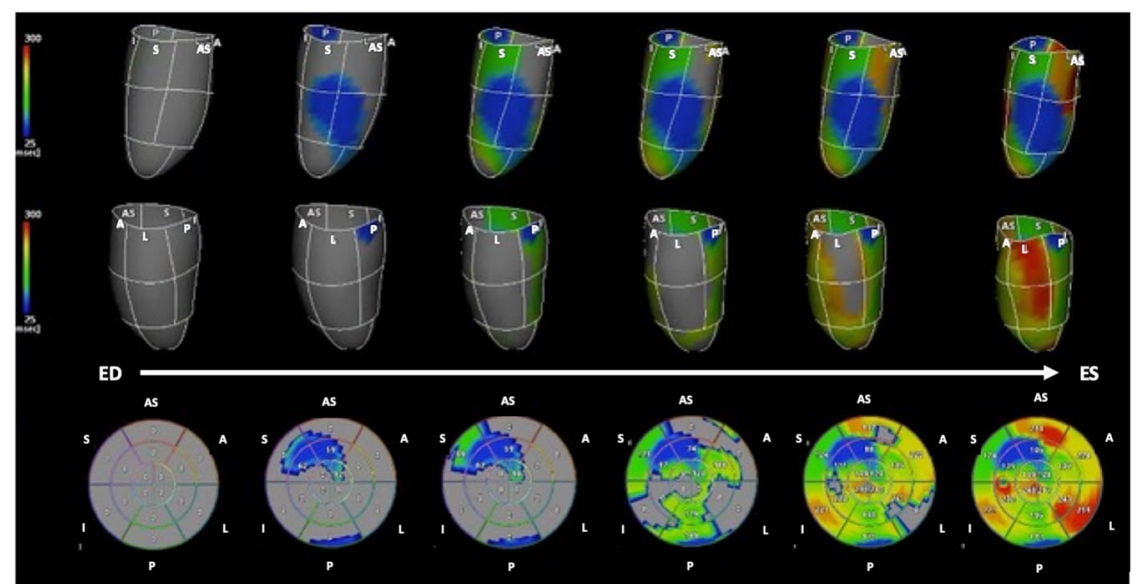

Fig. 7 Activation mapping. a: Propagation images in a normal subject by activation imaging with 3D speckle tracking echocardiography. The upper panel shows propagation of myocardial contraction viewed from the left ventricular (LV) septal side from end-diastole (ED) to end-systole (ES), and the lower panel shows it viewed from the LV free wall. The color bar refers to a color-coded time scale that corresponds to the timing of the onset of regional contractions. In this case, the range is set from $0 \mathrm{~ms}$ (dark blue) to $320 \mathrm{~ms}$ (red) via green and yellow. The onset of myocardial contraction in the entire left ventricle is almost synchronized, reflecting light green colored area spreading rapidly. b: Propagation images in a patient with left bundle branch block. The upper panel shows propagation of LV myocardial contraction viewed from the septal side, and the middle panel shows it viewed from the LV free wall. The lower panel is a bull's eye map displaying the spread of contraction. The upper panel shows early contraction in the septum colored in blue, which is earlier than septal contraction timing in normal subjects, and corresponds to "septal flash" during the pre-ejection period. The propagation of septal contraction is blocked at the anterior wall, but propagates toward the apex. The delayed propagation from the apex to the lateral wall is shown in a red-colored area in the basal to mid lateral wall, characterizing $\mathrm{U}$ shaped propagation. A, anterior wall; AS, anterior septum; I, inferior wall; L, lateral wall; P, posterior wall; S, septal wall 


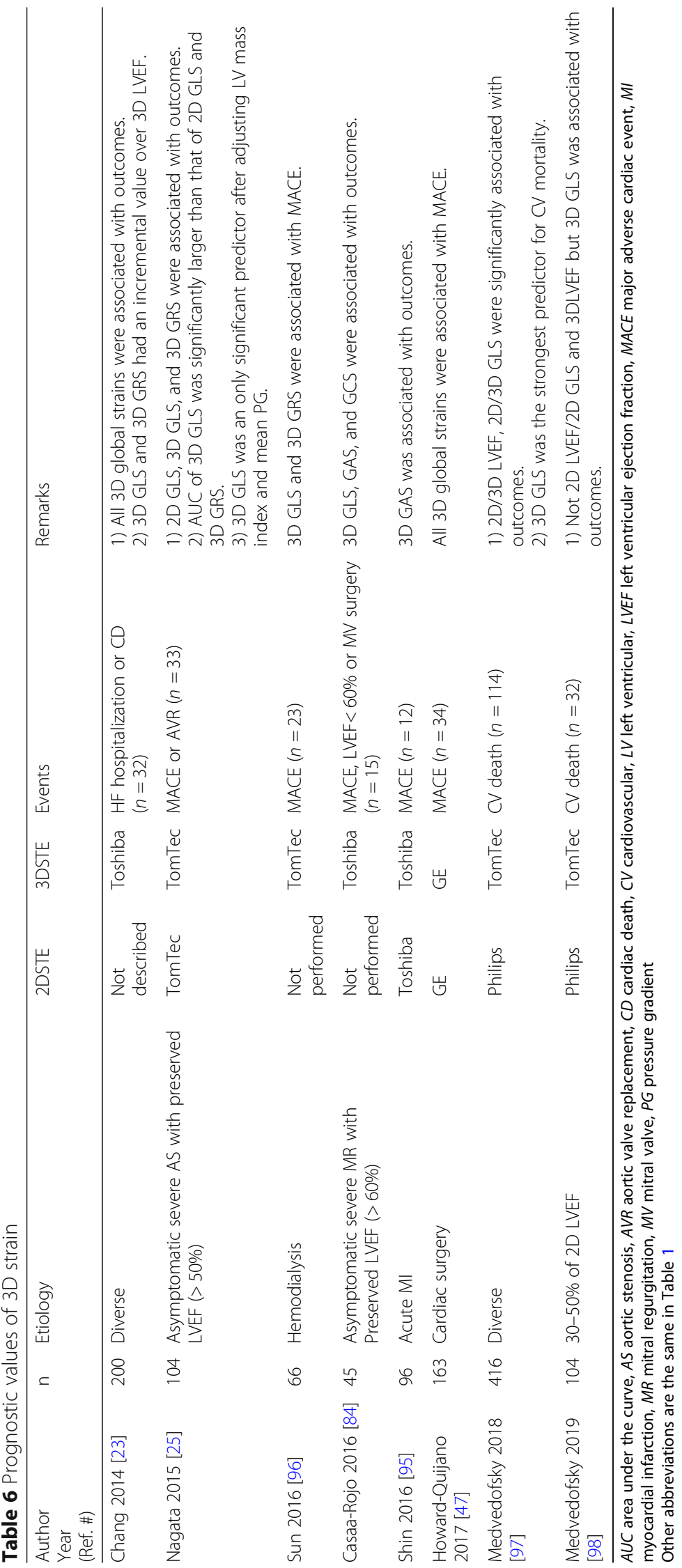


regional abnormalities in a 3D map. Stress CT perfusion was also color-coded to detect regional perfusion abnormalities. Fractional flow reserve (FFR) was also measured using CTCA. The presence of resting strain abnormalities had $71 \%$ sensitivity and $81 \%$ specificity for detecting $>50 \%$ stenosis in CTCA and stress-induced myocardial perfusion defects within specific coronary vascular beds. It had a sensitivity of $83 \%$ and a specificity of $81 \%$ for detecting stress-induced myocardial perfusion and FFR < 0.80 . These results suggest that fusion imaging with $3 \mathrm{D}$ strain and CTCA provide valuable information to detect functionally significant coronary stenosis, even at rest. Additional large-scale studies are required to validate whether 3D regional longitudinal strain abnormalities at rest reflect solely reductions of coronary blood flow due to functionally significant coronary stenosis.

\section{Future directions}

Like the 2D strain standardization taskforce [105-108], the American Society of Echocardiography/ EACVI and instrument partners should work together to identify causes of inter-vendor variability of 3D strain measurements with the objective of reducing it. Current 3D LV strain analysis is predominantly performed to evaluate global LV function. Segmental 3D strain abnormalities may represent specific pathologies. However, accurate $3 \mathrm{D}$ segmental tracking requires clearer 3D images with fine spatial resolution and high temporal resolution. Although one-beat acquisition of 3DE full-volume datasets using smaller $3 \mathrm{DE}$ transducers is now possible, spatial and temporal resolution are still not adequate to perform reliable segmental deformation analysis. This limitation also causes some underestimation of 3D global strain values, compared with corresponding 2D global strain values. Non-segmental (e.g., coronary artery territories) analysis of deformation is one solution to overcome current problems for segmental analysis [109]. Myocardial curvature analysis or LV shape analysis is another fruitful field of research, because it will provide useful information regarding disease severity and prognosis [99]. Since 3D strain simultaneously provides multidirectional strains, extraction of shear strain components which combine deformation in two different directions is also an interesting field for research $[7,110]$. $3 \mathrm{DE}$ could be more useful than 2DE in complex and irregular heart chambers, like the right ventricle. 3D strain software aimed at other cardiac chambers is just starting and is now commercially available. It will soon be determined whether 3D RV global strains are more robust parameters than 3D RVEF to predict future outcomes, and whether 3D RV global strains detect subtle RV dysfunction in patients whose 3D RVEF is still normal. Finally, fully automated 3D strain analytical software will eliminate observer variability of 3D strain measurements, and will facilitate the use of 3D strain for routine adoption in the clinical arena.

\section{Conclusions}

3D LV speckle tracking software simultaneously provides LV volumes, LVEF, and 3D global strains with multiple directions. It also provides a new 3D deformation parameter, such as area strain, which is an integral marker of longitudinal and circumferential function. However, 3DE data acquisition and subsequent strain analysis have not been widely adopted, and their evaluation is still limited to research applications. There are no consistent findings to suggest that $3 \mathrm{D} \mathrm{LV}$ strain is superior to $2 \mathrm{D} \mathrm{LV}$ strain in some clinical scenarios. In addition to facilitating further refinements of both 3DE image quality and 3D LV strain software, application of fully-automated 3D strain software may expand its adoption into routine echocardiography examinations.

\section{Supplementary information}

Supplementary information accompanies this paper at https://doi.org/10. 1186/s12947-020-00204-3.

Additional file 1: Figure S1. Forest plots of the mean difference in 2D GLS between patients with subclinical left ventricular dysfunction and control subjects (A), and corresponding 3D GLS values between the two groups (B) Each study shows first author's last name, year of publication, and the reference number (parenthesis). $\mathrm{Cl}$, confidence interval; $\mathrm{MD}$, mean difference; SD, standard deviation.

\section{Abbreviations}

2D: Two-dimensional; 3D: Three-dimensional; 2DE: Two-dimensional echocardiography; 3DE: Three-dimensional echocardiography; CRT: Cardiac resynchronization therapy; CTCA: Computed tomography coronary angiography; EACVI: European Association of Cardiovascular Imaging; FFR: Fractional flow reserve; GAS: Global area strain; GCS: Global circumferential strain; GLS: Global longitudinal strain; GRS: Global radial strain; LLN: Lower limit normal; LGE: Late gadolinium enhancement; LV: Left ventricular; LVEF: Left ventricular ejection fraction; LVH: Left ventricular hypertrophy; ROI: Region of interest

\section{Acknowledgements}

We thank Dr. Tetsuji Kitano for contributing data collection.

\section{Authors' contributions}

YN Data collection, Data analysis, Preparing figures, YS Supervision, Preparing figures, MT Concept, Data analysis, Data collection, Drafting article, Critical revision of article. The author(s) read and approved the final manuscript.

\section{Funding}

Not applicable.

\section{Availability of data and materials}

The datasets used and analyzed during current study are available from the corresponding author on reasonable request.

Ethics approval and consent to participate Not applicable.

Consent for publication

All authors read and approved the final manuscript.

Competing interests

The authors declare that they have no competing interests. 


\section{Author details}

${ }^{1}$ Second Department of Internal Medicine, School of Medicine, University of Occupational and Environmental Health, 1-1 Iseigaoka, Yahatanishi, Kitakyushu 807-8555, Japan. ${ }^{2}$ Department of Cardiology, Graduate School of Medical Sciences, Nagoya City University, Nagoya, Japan. ${ }^{3}$ Department of Laboratory and Transfusion Medicine, School of Medicine, Hospital of University of Occupational and Environmental Health, Kitakyushu, Japan.

\section{Received: 30 March 2020 Accepted: 15 June 2020}

Published online: 26 June 2020

\section{References}

1. Geyer H, Caracciolo G, Abe H, Wilansky S, Carerj S, Gentile F, et al. Assessment of myocardial mechanics using speckle tracking echocardiography: fundamentals and clinical applications. J Am Soc Echocardiogr. 2010;23(4):351-69 quiz 453-5.

2. Smiseth OA, Torp H, Opdahl A, Haugaa KH, Urheim S. Myocardial strain imaging: how useful is it in clinical decision making? Eur Heart J. 2016; 37(15):1196-207

3. Voigt J-U, Cvijic M. 2- and 3-dimensional myocardial strain in cardiac health and disease. J Am Coll Cardiol Img. 2019;12(9):1849-63.

4. Jasaityte R, Heyde B, D'hooge J. Current state of three-dimensional myocardial strain estimation using echocardiography. J Am Soc Echocardiogr. 2013;26(1):15-28.

5. Muraru D, Niero A, Rodriguez-Zanella H, Cherata D, Badano L. Threedimensional speckle-tracking echocardiography: benefits and limitations of integrating myocardial mechanics with three-dimensional imaging. Cardiovasc Diagn Ther. 2018;8(1):101-17.

6. Galderisi M, Esposito R, Schiano-Lomoriello V, Santoro A, Ippolito R, Schiattarella $\mathrm{P}$, et al. Correlates of global area strain in native hypertensive patients: a three-dimensional speckle-tracking echocardiography study. Eur Heart J Cardiovasc Imaging. 2012;13(9):730-8.

7. Pedrizzetti G, Sengupta S, Caracciolo G, Park CS, Amaki M, Goliasch G, et al. Three-dimensional principal strain analysis for characterizing subclinical changes in left ventricular function. J Am Soc Echocardiogr. 2014;27(10): 1041-50 e1

8. Gayat E, Ahmad H, Weinert L, Lang RM, Mor-Avi V. Reproducibility and intervendor variability of left ventricular deformation measurements by threedimensional speckle-tracking echocardiography. J Am Soc Echocardiogr. 2011;24(8):878-85

9. Takigiku K, Takeuchi M, Izumi C, Yuda S, Sakata K, Ohte N, et al. Normal range of left ventricular 2-dimensional strain: Japanese ultrasound speckle tracking of the left ventricle (JUSTICE) study. Circ J. 2012;76(11):2623-32.

10. Sugimoto T, Dulgheru R, Bernard A, llardi F, Contu L, Addetia K, et al. Echocardiographic reference ranges for normal left ventricular 2D strain: results from the EACVI NORRE study. Eur Heart J Cardiovasc Imaging. 2017; 18(8):833-40.

11. Asch FM, Miyoshi T, Addetia K, Citro R, Daimon M, Desale S, et al. Similarities and Differences in Left Ventricular Size and Function among Races and Nationalities: Results of the World Alliance Societies of Echocardiography Normal Values Study. J Am Soc Echocardiogr. 2019;32(11):1396-406 e2.

12. D'Elia N, Caselli S, Kosmala W, Lancellotti P, Morris D, Muraru D, et al. Normal global longitudinal strain: an individual patient meta-analysis. J Am Coll Cardiol Img. 2020;13(1):167-9.

13. Wu VC-C, Takeuchi M, Otani K, Haruki N, Yoshitani H, Tamura M, et al. Effect of through-plane and twisting motion on left ventricular strain calculation: direct comparison between two-dimensional and three-dimensional speckle-tracking echocardiography. J Am Soc Echocardiogr. 2013;26(11): 1274-81 e4.

14. Seo $Y$, Ishizu T, Enomoto $Y$, Sugimori H, Yamamoto M, Machino T, et al. Validation of 3-dimensional speckle tracking imaging to quantify regional myocardial deformation. Circ Cardiovasc Imaging. 2009;2(6):451-9.

15. Seo $Y$, Ishizu T, Enomoto $Y$, Sugimori H, Aonuma K. Endocardial surface area tracking for assessment of regional LV Wall deformation with 3D speckle tracking imaging. J Am Coll Cardiol Img. 2011;4(4):358-65.

16. Kleijn SA, Brouwer WP, Aly MFA, Rüssel IK, de Roest GJ, Beek AM, et al. Comparison between three-dimensional speckle-tracking echocardiography and cardiac magnetic resonance imaging for quantification of left ventricular volumes and function. Eur Heart J Cardiovasc Imaging. 2012; 13(10):834-9.
17. Luis SA, Yamada A, Khandheria BK, Speranza V, Benjamin A, Ischenko M, et al. Use of three-dimensional speckle-tracking echocardiography for quantitative assessment of global left ventricular function: a comparative study to three-dimensional echocardiography. J Am Soc Echocardiogr. 2014; 27(3):285-91.

18. Obokata M, Nagata Y, Wu VC-C, Kado Y, Kurabayashi M, Otsuji Y, et al. Direct comparison of cardiac magnetic resonance feature tracking and 2D/3D echocardiography speckle tracking for evaluation of global left ventricular strain. Eur Heart J Cardiovasc Imaging. 2016;17(5):525-32.

19. Mor-Avi V, Lang RM, Badano LP, Belohlavek M, Cardim NM, Derumeaux G, et al. Current and evolving echocardiographic techniques for the quantitative evaluation of cardiac mechanics: ASE/EAE consensus statement on methodology and indications endorsed by the Japanese Society of Echocardiography. Eur Heart J Cardiovasc Imaging. 2011;12(3):167-205.

20. Ajmone Marsan N, Michalski B, Cameli M, Podlesnikar T, Manka R, Sitges M, et al. EACVI survey on standardization of cardiac chambers quantification by transthoracic echocardiography. Eur Heart J Cardiovasc Imaging. 2019;21(2): 119-23.

21. Negishi K, Negishi T, Agler DA, Plana JC, Marwick TH. Role of temporal resolution in selection of the appropriate strain technique for evaluation of subclinical myocardial dysfunction. Echocardiogr. 2011;29(3):334-9.

22. Reant $P$, Barbot $L$, Touche C, Dijos M, Arsac F, Pillois X, et al. Evaluation of global left ventricular systolic function using three-dimensional echocardiography speckle-tracking strain parameters. J Am Soc Echocardiogr. 2012;25(1):68-79.

23. Altman M, Bergerot C, Aussoleil A, Davidsen ES, Sibellas F, Ovize M, et al. Assessment of left ventricular systolic function by deformation imaging derived from speckle tracking: a comparison between 2D and 3D echo modalities. Eur Heart J Cardiovasc Imaging. 2014;15(3):316-23.

24. Chang S-N, Lai Y-H, Yen C-H, Tsai C-T, Lin J-W, Bulwer BE, et al. CardiaC mechanics and ventricular twist by three-dimensional strain analysis in relation to B-type natriuretic peptide as a clinical prognosticator for heart failure patients. PLoS One. 2014;9(12):e115260.

25. Xu T-Y, Sun JP, Lee AP-W, Yang XS, Qiao Z, Luo X, et al. Three-dimensional speckle strain echocardiography is more accurate and efficient than $2 \mathrm{D}$ strain in the evaluation of left ventricular function. Int J Cardiol. 2014;176(2): 360-6.

26. Nagata Y, Takeuchi M, Wu VC-C, Izumo M, Suzuki K, Sato K, et al. Prognostic value of $L V$ deformation parameters using $2 \mathrm{D}$ and $3 \mathrm{D}$ speckle-tracking echocardiography in asymptomatic patients with severe aortic stenosis and preserved LV ejection fraction. J Am Coll Cardiol Img. 2015;8(3):235-45.

27. Santoro C, Arpino G, Esposito R, Lembo M, Paciolla I, Cardalesi C, et al. 2D and $3 \mathrm{D}$ strain for detection of subclinical anthracycline cardiotoxicity in breast cancer patients: a balance with feasibility. Eur Heart J Cardiovasc Imaging. 2017;18(8):930-6.

28. Xu L, Huang X, Ma J, Huang J, Fan Y, Li H, et al. Value of three-dimensional strain parameters for predicting left ventricular remodeling after STelevation myocardial infarction. Int J Cardiovasc Imaging. 2017;33(5):663-73.

29. Amzulescu MS, Langet $H$, Saloux E, Manrique A, Slimani A, Allain $P$, et al. Improvements of Myocardial Deformation Assessment by ThreeDimensional Speckle-Tracking versus Two-Dimensional Speckle-Tracking Revealed by Cardiac Magnetic Resonance Tagging. J Am Soc Echocardiogr. 2018;31(9):1021-33 e1.

30. Saito K, Okura H, Watanabe N, Hayashida A, Obase K, Imai K, et al. Comprehensive evaluation of left ventricular strain using speckle tracking echocardiography in Normal adults: comparison of three-dimensional and two-dimensional approaches. J Am Soc Echocardiogr. 2009;22(9):1025-30.

31. Hayat D, Kloeckner M, Nahum J, Ecochard-Dugelay E, Dubois-Randé J-L, Jean-François D, et al. Comparison of real-time three-dimensional speckle tracking to magnetic resonance imaging in patients with coronary heart disease. Am J Cardiol. 2012;109(2):180-6.

32. Matsumoto K, Tanaka H, Kaneko A, Ryo K, Fukuda Y, Tatsumi K, et al. Contractile reserve assessed by three-dimensional global circumferential strain as a predictor of cardiovascular events in patients with idiopathic dilated cardiomyopathy. J Am Soc Echocardiogr. 2012;25(12):1299-308.

33. Ternacle J, Gallet R, Champagne S, Teiger E, Gellen B, Dubois-Randé J-L, et al. Changes in three-dimensional speckle-tracking-derived myocardial strain during percutaneous coronary intervention. J Am Soc Echocardiogr. 2013;26(12):1444-9.

34. Thorstensen A, Dalen H, Hala P, Kiss G, D\&apos, Hooge J, Torp H, et al. Three-dimensional echocardiography in the evaluation of global and 
regional function in patients with recent myocardial infarction: a comparison with magnetic resonance imaging. Echocardiogr 2013;30(6): 682-692.

35. Urbano-Moral JA, Arias-Godinez JA, Ahmad R, Malik R, Kiernan MS, DeNofrio $D$, et al. Evaluation of myocardial mechanics with three-dimensional speckle tracking echocardiography in heart transplant recipients: comparison with two-dimensional speckle tracking and relationship with clinical variables. Eur Heart J Cardiovasc Imaging. 2013;14(12):1167-73.

36. Tadic M, Cuspidi C, Backovic S, Kleut M, Ivanovic B, Scepanovic R, et al High-normal blood pressure, functional capacity and left heart mechanics: is there any connection? Blood Press. 2014;23(5):315-21.

37. Tadic M, Cuspidi C, Pencic B, Pavlovic SU, Ivanovic B, Kocijancic V, et al. Association between left ventricular mechanics and heart rate variability in untreated hypertensive patients. J Clin Hypertens. 2014;17(2):118-25.

38. Trache T, Stöbe S, Tarr A, Pfeiffer D, Hagendorff A. The agreement between $3 \mathrm{D}$, standard $2 \mathrm{D}$ and triplane $2 \mathrm{D}$ speckle tracking: effects of image quality and 3D volume rate. Echo Res Pract. 2014;1(2):71-83.

39. Tadic M, Cuspidi C, Majstorovic A, Kocijancic V, Celic V. The relationship between left ventricular deformation and different geometric patterns according to the updated classification. J Hypertens. 2015;33(9):1954-61.

40. Tarr A, Stoebe S, Tuennemann J, Baka Z, Pfeiffer D, Varga A, et al. Early detection of cardiotoxicity by $2 \mathrm{D}$ and $3 \mathrm{D}$ deformation imaging in patients receiving chemotherapy. Echo Res Pract. 2015;2(3):81-8.

41. Vitarelli A, Mangieri E, Capotosto L, Tanzilli G, D\&apos;Angeli I, Viceconte N, et al. Assessment of biventricular function by three-dimensional speckletracking echocardiography in secondary mitral regurgitation after repair with the MitraClip system. J Am Soc Echocardiogr 2015;28(9):1070-1082.

42. Wang Q, Huang D, Zhang L, Shen D, Ouyang Q, Duan Z, et al. Assessment of myocardial infarct size by three-dimensional and two-dimensional speckle tracking echocardiography: a comparative study to single photon emission computed tomography. Echocardiogr. 2015;32(10):1539-46.

43. D'Ascenzi F, Solari M, Mazzolai M, Cameli M, Lisi M, Andrei V, et al. Twodimensional and three-dimensional left ventricular deformation analysis: a study in competitive athletes. Int J Cardiovasc Imaging. 2016;32(12):1697705.

44. Tadic M, Cuspidi C, Ivanovic B, Ilic I, Kocijancic V. Influence of white-coat hypertension on left ventricular deformation 2- and 3-dimensional speckle tracking study. Hypertension. 2016:67:592-6.

45. Tadic M, Cuspidi C, Pencic B, Andric A, Pavlovic SU, Iracek O, et al. The interaction between blood pressure variability, obesity, and left ventricular mechanics. J Hypertens. 2016;34(4):772-80.

46. Ahn H-S, Kim Y-K, Song HC, Choi EJ, Kim G-H, Cho JS, et al. The impact of preload on 3-dimensional deformation parameters: principal strain, twist and torsion. Cardiovasc Ultrasound. 2017;15(1):22-12.

47. Cho EJ, Park S-J, Kim EK, Lee GY, Chang S-A, Choi J-O, et al. Effects of increased left ventricular wall thickness on the myocardium in severe aortic stenosis with normal left ventricular ejection fraction: two- and threedimensional multilayer speckle tracking echocardiography. Echocardiogr. 2017;34(4):511-22

48. Howard Quijano K, Salem A, Barkulis C, Mazor E, Scovotti JC, Ho JK, et al. Preoperative three-dimensional strain imaging identifies reduction in left ventricular function and predicts outcomes after cardiac surgery. Anesth Analg. 2017:124(2):419-28.

49. Ringle A, Dornhorst A, Rehman MB, Ruisanchez C, Nihoyannopoulos P. Evolution of subclinical myocardial dysfunction detected by two-dimensional and three-dimensional speckle tracking in asymptomatic type 1 diabetic patients: a long-term follow-up study. Echo Res Pract. 2017:4(4):73-81.

50. Sugano A, Seo Y, Ishizu T, Watabe H, Yamamoto M, Machino-Ohtsuka T, et al. Value of 3-dimensional speckle tracking echocardiography in the prediction of microvascular obstruction and left ventricular remodeling in patients with ST-elevation myocardial infarction. Circ J. 2017;81(3):353-60.

51. Szulik M, FLiwiñska A, Lenarczyk R, Szyma AM, Kalinowski ME, Markowicz-

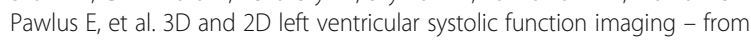
ejection fraction to deformation. Cardiac resynchronization therapy substudy. Acta Cardiol. 2017;70(1):21-30

52. Tadic M, Zlatanovic M, Cuspidi C, Ivanovic B, Stevanovic A, Damjanov N, et al. The relationship between left ventricular deformation and heart rate variability in patients with systemic sclerosis: two- and three-dimensional strain analysis. Int J Cardiol. 2017;236:145-50.

53. Ternacle J, Bremont C, d'Humieres T, Faivre L, Doan HL, Gallet R, et al. Left ventricular dyssynchrony and 2D and 3D global longitudinal strain for differentiating physiological and pathological left ventricular hypertrophy. Arch Cardiovasc Dis. 2017;110(6-7):403-12.

54. Cruz MC, Branco LM, Portugal G, Galrinho A, Timóteo AT, Rio P, et al. Threedimensional speckle-tracking echocardiography for the global and regional assessments of left ventricle myocardial deformation in breast cancer patients treated with anthracyclines. Clin Res Cardiol. 2019;97:1-12.

55. Pavlovic-Kleut M, Sljivic A, Celic V. Left ventricle ejection fraction and strain derived by three-dimensional echocardiography are associated with exercise capacity in the patients with heart failure. Vojnosanit Pregl. 2019; 76(8):779-86.

56. Celic V, Tadic M, Suzic-Lazic J, Andric A, Majstorovic A, Ivanovic B, et al. Twoand three-dimensional speckle tracking analysis of the relation between myocardial deformation and functional capacity in patients with systemic hypertension. Am J Cardiol. 2014;113(5):832-9.

57. Perez de Isla L, Balcones DV, Fernandez-Golfin C, Marcos-Alberca P, Almeria C, Rodrigo JL, et al. Three-dimensional-wall motion tracking: a new and faster tool for myocardial strain assessment: comparison with two-dimensional-wall motion tracking. J Am Soc Echocardiogr. 2009;22(4):325-30.

58. Truong VT, Phan HT, Pham KNP, Duong HNH, Ngo TNM, Palmer C, et al. Normal Ranges of Left Ventricular Strain by Three-Dimensional SpeckleTracking Echocardiography in Adults: A Systematic Review and MetaAnalysis. J Am Soc Echocardiogr. 2019;32(12):1586-97 e5.

59. Muraru D, Cucchini U, Mihăilă S, Miglioranza MH, Aruta P, Cavalli G, et al. Left ventricular myocardial strain by three-dimensional speckle-tracking echocardiography in healthy subjects: reference values and analysis of their physiologic and technical determinants. J Am Soc Echocardiogr. 2014;27(8): 858-71 e1.

60. Kaku K, Takeuchi M, Tsang W, Takigiku K, Yasukochi S, Patel AR, et al. Agerelated normal range of left ventricular strain and torsion using threedimensional speckle-tracking echocardiography. J Am Soc Echocardiogr. 2014;27(1):55-64.

61. J-z X, J-y X, Li G, Ma W-y, Wang Q-q. Left ventricular strain examination of different aged adults with 3D speckle tracking echocardiography. Echocardiogr. 2014;31(3):335-9.

62. Kleijn SA, Pandian NG, Thomas JD, Perez de Isla L, Kamp O, Zuber M, et al. Normal reference values of left ventricular strain using three-dimensional speckle tracking echocardiography: results from a multicentre study. Eur Heart J Cardiovasc Imaging. 2015;16(4):410-6.

63. Bernard A, Addetia K, Dulgheru R, Caballero L, Sugimoto T, Akhaladze N, et al. 3D echocardiographic reference ranges for normal left ventricular volumes and strain: results from the EACVI NORRE study. Eur Heart J Cardiovasc Imaging. 2017;18(4):475-83.

64. Kovács Z, Kormányos Á, Domsik P, Kalapos A, Lengyel C, Ambrus N, et al. Left ventricular longitudinal strain is associated with mitral annular fractional area change in healthy subjects-results from the three-dimensional speckle tracking echocardiographic MAGYAR-healthy study. Quant Imaging in Med Surg. 2019;9(2):304-11.

65. Badano LP, Cucchini U, Muraru D, Nono OA, Sarais C, lliceto S. Use of threedimensional speckle tracking to assess left ventricular myocardial mechanics: inter-vendor consistency and reproducibility of strain measurements. Eur Heart J Cardiovasc Imaging. 2013;14(3):285-93.

66. Abate E, Hoogslag GE, Antoni ML, Nucifora G, Delgado V, Holman ER, et al. Value of three-dimensional speckle-tracking longitudinal strain for predicting improvement of left ventricular function after acute myocardial infarction. Am J Cardiol. 2012;110(7):961-7.

67. Li X-C, Jin F-L, Jing C, Xiao Q, Liu Y, Ran Z-S, et al. Predictive value of left ventricular remodeling by area strain based on three-dimensional wallmotion tracking after $\mathrm{PCl}$ in patients with recent NSTEMI. Ultrasound Med \& Biol. 2012;38(9):1491-501.

68. Zhu W, Liu W, Tong Y, Xiao J. Three-dimensional speckle tracking echocardiography for the evaluation of the infarct size and segmental transmural involvement in patients with acute myocardial infarction. Echocardiogr. 2014;31(1):58-66.

69. Aly MFA, Kleijn SA, Menken-Negroiu RF, Robbers LF, Beek AM, Kamp O. Three-dimensional speckle tracking echocardiography and cardiac magnetic resonance for left ventricular chamber quantification and identification of myocardial transmural scar. Neth Heart J. 2016;24(10):600-8.

70. K-y D, Yang Z-g, Ma M, He Y, Zhao Q, Liu X, et al. The diagnostic value of global longitudinal strain (GLS) on myocardial infarction size by echocardiography: a systematic review and meta-analysis. Sci Rep. 2017;7(1): $1-8$. 
71. Plana JC, Galderisi M, Barac A, Ewer MS, Ky B, Scherrer-Crosbie M, et al. Expert consensus for multimodality imaging evaluation of adult patients during and after cancer therapy: a report from the American Society of Echocardiography and the European Association of Cardiovascular Imaging. Eur Heart J Cardiovasc Imaging. 2014;15(10):1063-93.

72. Thavendiranathan P, Poulin F, Lim K-D, Plana JC, Woo A, Marwick TH. Use of myocardial strain imaging by echocardiography for the early detection of cardiotoxicity in patients during and after cancer chemotherapy: a systematic review. J Am Coll Cardiol. 2014;63(25 Pt A):2751-68.

73. Mornos C, Manolis A, Cozma D, Kouremenos N, Zacharopoulou I, lonac A. The Value of Left Ventricular Global Longitudinal Strain Assessed by ThreeDimensional Strain Imaging in the Early Detection of AnthracyclineMediated Cardiotoxicity. Hellenic J Cardiol. 2014;55:235-44.

74. Song F-Y, Shi J, Zhang C-J, Xu Y-C, Zhang Q-L, Shu X-H, et al. Assessment of biventricular systolic strain derived from the two- dimensional and threedimensional speckle tracking echocardiography in lymphoma patients after anthracycline therapy. Int J Cardiovasc Imaging. 2017:33(6):857-68.

75. Zhang KW, Finkelman BS, Gulati G, Narayan HK, Upshaw J, Narayan V, et al. Abnormalities in 3-dimensional left ventricular mechanics with Anthracycline chemotherapy are associated with systolic and diastolic dysfunction. J Am Coll Cardiol Img. 2018;11(8):1059-68.

76. Chen J, Wang L, Wu FF, Sun G. Early detection of cardiotoxicity by 3D speckle tracking imaging of area strain in breast cancer patients receiving chemotherapy. Echocardiogr. 2019;36(9):1682-8.

77. Enomoto M, Ishizu T, Seo Y, Kameda Y, Suzuki H, Shimano H, et al. Myocardial dysfunction identified by three-dimensional speckle tracking echocardiography in type 2 diabetes patients relates to complications of microangiopathy. J Cardiol. 2016;68(4):282-7

78. Levy D, Garrison RJ, Savage DD, Kannel WB, Castelli WP. Prognostic implications of echocardiographically determined left ventricular mass in the Framingham heart study. N Engl J Med. 1990;322(22):1561-6.

79. Baccouche H, Maunz M, Beck T, Gaa E, Banzhaf M, Knayer U, et al. Differentiating cardiac amyloidosis and hypertrophic cardiomyopathy by use of three-dimensional speckle tracking echocardiography. Echocardiogr. 2012;29(6):668-77.

80. Aly MFA, Brouwer WP, Kleijn SA, van Rossum AC, Kamp O. Threedimensional speckle tracking echocardiography for the preclinical diagnosis of hypertrophic cardiomyopathy. Int J Cardiovasc Imaging. 2014;30(3):52333

81. Urbano-Moral JA, Gangadharamurthy D, Comenzo RL, Pandian NG, Patel AR Three-dimensional speckle tracking echocardiography in light chain cardiac amyloidosis: examination of left and right ventricular myocardial mechanics parameters. Rev Esp Cardiol. 2015;68(8):657-64.

82. Voilliot D, Huttin O, Hammache N, Filippetti L, Vaugrenard T, Aliot E, et al. Impact of global and segmental hypertrophy on two-dimensional strain derived from three-dimensional echocardiography in hypertrophic cardiomyopathy: comparison with healthy subjects. J Am Soc Echocardiogr. 2015;28(9):1093-102

83. Pradel S, Magne J, Jaccard A, Fadel BM, Boulogne C, Salemi VMC, et al. Left ventricular assessment in patients with systemic light chain amyloidosis: a 3-dimensional speckle tracking transthoracic echocardiographic study. Int Cardiovasc Imaging. 2019;35(5):845-54.

84. Phelan D, Collier P, Thavendiranathan P, Popovic ZB, Hanna M, Plana JC, et al. Relative apical sparing of longitudinal strain using two-dimensional speckle-tracking echocardiography is both sensitive and specific for the diagnosis of cardiac amyloidosis. Heart. 2012;98(19):1442-8.

85. Schueler R, Sinning J-M, Momcilovic D, Weber M, Ghanem A, Werner N, et al. Three-dimensional speckle-tracking analysis of left ventricular function after transcatheter aortic valve implantation. J Am Soc Echocardiogr. 2012; 25(8):827-34 e1.

86. Casas-Rojo E, Fernandez-Golfin C, Moya-Mur J-L, González-Gómez A, GarcíaMartín A, Morán-Fernández L, et al. Area strain from 3D speckle-tracking echocardiography as an independent predictor of early symptoms or ventricular dysfunction in asymptomatic severe mitral regurgitation with preserved ejection fraction. Int J Cardiovasc Imaging. 2016;32(8):1189-98.

87. Scandura S, Dipasqua F, Gargiulo G, Capodanno D, Caggegi A, Grasso C, et al. Early results of MitraClip system implantation by real-time threedimensional speckle-tracking left ventricle analysis. J Cardiovasc Med. 2016; 17(11):843-9.

88. Broch K, de Marchi SF, Massey R, Hisdal J, Aakhus S, Gullestad L, et al. Left Ventricular Contraction Pattern in Chronic Aortic Regurgitation and
Preserved Ejection Fraction: Simultaneous Stress-Strain Analysis by ThreeDimensional Echocardiography. J Am Soc Echocardiogr. 2017;30(4):422-30 e2.

89. Bax JJ, Gorcsan J. Echocardiography and noninvasive imaging in cardiac resynchronization therapy: results of the PROSPECT (predictors of response to cardiac resynchronization therapy) study in perspective. J Am Coll Cardiol. 2009;53(21):1933-43.

90. Tanaka H, Hara H, Adelstein EC, Schwartzman D, Saba S, Gorcsan J. Comparative mechanical activation mapping of RV pacing to LBBB by $2 \mathrm{D}$ and $3 \mathrm{D}$ speckle tracking and association with response to resynchronization therapy. J Am Coll Cardiol Img. 2010;3(5):461-71.

91. Tanaka H, Hara H, Saba S, Gorcsan J. Usefulness of three-dimensional speckle tracking strain to quantify dyssynchrony and the site of latest mechanical activation. Am J Cardiol. 2010;105(2):235-42.

92. Tatsumi K, Tanaka H, Matsumoto K, Hiraishi M, Miyoshi T, Tsuji T, et al. Mechanical left ventricular dyssynchrony in heart failure patients with narrow QRS duration as assessed by three-dimensional speckle area tracking strain. Am J Cardiol. 2011;108(6):867-72.

93. Tatsumi K, Tanaka H, Tsuji T, Kaneko A, Ryo K, Yamawaki K, et al. Strain dyssynchrony index determined by three-dimensional speckle area tracking can predict response to cardiac resynchronization therapy. Cardiovasc Ultrasound. 2011;9(1):11.

94. Thebault C, Donal E, Bernard A, Moreau O, Schnell F, Mabo P, et al. Realtime three-dimensional speckle tracking echocardiography: a novel technique to quantify global left ventricular mechanical dyssynchrony. Eur J Echocardiogr. 2011;12(1):26-32.

95. Seo Y, Yamasaki H, Kawamura R, Ishizu T, Igarashi M, Sekiguchi Y, et al. Left ventricular activation imaging by 3-dimensional speckle-tracking echocardiography. Comparison with electrical activation mapping. Circ J. 2013;77(10):2481-9.

96. Seo $Y$, Ishizu T, Kawamura R, Yamamoto M, Kuroki K, Igarashi M, et al. Threedimensional propagation imaging of left ventricular activation by speckletracking echocardiography to predict responses to cardiac resynchronization therapy. J Am Soc Echocardiogr. 2015;28(5):606-14.

97. Shin SH, Suh YJ, Baek Y-S, Lee M-J, Park S-D, Kwon S-W, et al. Impact of area strain by 3D speckle tracking on clinical outcome in patients after acute myocardial infarction. Echocardiography (Mount Kisco, NY). 2016;33(12):1854-9.

98. Sun M, Kang Y, Cheng L, Pan C, Cao X, Yao H, et al. Global longitudinal strain is an independent predictor of cardiovascular events in patients with maintenance hemodialysis: a prospective study using three-dimensional speckle tracking echocardiography. Int J Cardiovasc Imaging. 2016;32(5): 757-66.

99. Medvedofsky D, Maffessanti F, Weinert L, Tehrani DM, Narang A, Addetia K, et al. 2D and 3D echocardiography-derived indices of left ventricular function and shape: relationship with mortality. J Am Coll Cardiol Img. 2018; 11(11):1569-79.

100. Medvedofsky D, Lang RM, Weinert L, Tehrani DM, Narang A, Mor-Avi V. 3D echocardiographic global longitudinal strain can identify patients with mildly-to-moderately reduced ejection fraction at higher cardiovascular risk. Int J Cardiovasc Imaging. 2019;35(9):1573-9.

101. Weidemann F, Herrmann S, Störk S, Niemann M, Frantz S, Lange V, et al. Impact of myocardial fibrosis in patients with symptomatic severe aortic stenosis. Circulation. 2009:120(7):577-84.

102. Tavard F, Simon A, Leclercq C, Donal E, Hernandez Al, Garreau M. Multimodal registration and data fusion for cardiac resynchronization therapy optimization. IEEE Trans Med Imaging. 2014;33(6):1363-72.

103. Maffessanti F, Patel AR, Patel MB, Walter JJ, Mediratta A, Medvedofsky D, et al. Non-invasive assessment of the haemodynamic significance of coronary stenosis using fusion of cardiac computed tomography and 3D echocardiography. Eur Heart J Cardiovasc Imaging. 2017;18:670-80.

104. Mor-Avi V, Patel MB, Maffessanti F, Singh A, Medvedofsky D, Zaidi SJZ, et al. Fusion of three-dimensional echocardiographic regional myocardial strain with cardiac computed tomography for noninvasive evaluation of the hemodynamic impact of coronary stenosis in patients with chest pain. J Am Soc Echocardiogr. 2018;31(6):664-73.

105. Farsalinos KE, Daraban AM, Ünlü S, Thomas JD, Badano LP, Voigt J-U. Headto-Head Comparison of Global Longitudinal Strain Measurements among Nine Different Vendors: The EACVI/ASE Inter-Vendor Comparison Study. J Am Soc Echocardiogr. 2015;28(10):1171-81 e2.

106. Voigt JU, Pedrizzetti G, Lysyansky P, Marwick TH, Houle H, Baumann R, et al. Definitions for a common standard for 2D speckle tracking 
echocardiography: consensus document of the EACVI/ASE/industry task force to standardize deformation imaging. Eur Heart J Cardiovasc Imaging. 2015;16(1):1-11.

107. Mirea O, Pagourelias ED, Duchenne J, Bogaert J, Thomas JD, Badano LP, et al. Intervendor differences in the accuracy of detecting regional functional abnormalities. J Am Coll Cardiol Img. 2018;11(1):25-34.

108. Ünlü S, Mirea O, Duchenne J, Pagourelias ED, Bézy S, Thomas JD, et al. Comparison of Feasibility, Accuracy, and Reproducibility of Layer-Specific Global Longitudinal Strain Measurements Among Five Different Vendors: A Report from the EACVI-ASE Strain Standardization Task Force. J Am Soc Echocardiogr. 2018;31(3):374-80 e1.

109. de Knegt MC, Fuchs A, Weeke P, Mogelvang R, Hassager C, Kofoed KF. Optimisation of coronary vascular territorial 3D echocardiographic strain imaging using computed tomography: a feasibility study using image fusion. Int J Cardiovasc Imaging. 2016;32(12):1715-23.

110. Mangual JO, De Luca A, Domenichini F, Galanti G, Pedrizzetti G. Threedimensional reconstruction of the functional strain-line pattern in the left ventricle from 3-dimensional echocardiography. Circ Cardiovasc Imaging. 2012:5:808-9.

\section{Publisher's Note}

Springer Nature remains neutral with regard to jurisdictional claims in published maps and institutional affiliations.

Ready to submit your research? Choose BMC and benefit from:

- fast, convenient online submission

- thorough peer review by experienced researchers in your field

- rapid publication on acceptance

- support for research data, including large and complex data types

- gold Open Access which fosters wider collaboration and increased citations

- maximum visibility for your research: over $100 \mathrm{M}$ website views per year

At $\mathrm{BMC}$, research is always in progress.

Learn more biomedcentral.com/submissions 